Julia Even*, Alexander Yakushev, Christoph Emanuel Düllmann, Jan Dvorak, Robert Eichler, Oliver Gothe, Willy Hartmann, Daniel Hild, Egon Jäger, Jadambaa Khuyagbaatar, Birgit Kindler, Jens Volker Kratz, Jörg Krier, Bettina Lommel, Lorenz Niewisch, Heino Nitsche, Inna Pysmenetska, Matthias Schädel, Brigitta Schausten, Andreas Türler, Norbert Wiehl, and David Wittwer

\title{
In-situ formation, thermal decomposition, and adsorption studies of transition metal carbonyl complexes with short-lived radioisotopes
}

\begin{abstract}
We report on the in-situ synthesis of metal carbonyl complexes with short-lived isotopes of transition metals. Complexes of molybdenum, technetium, ruthenium and rhodium were synthesized by thermalisation of products of neutron-induced fission of ${ }^{249} \mathrm{Cf}$ in a carbon monoxide-nitrogen mixture. Complexes of tungsten, rhenium, osmium, and iridium were synthesized by thermalizing short-lived isotopes produced in ${ }^{24} \mathrm{Mg}$-induced fusion evaporation reactions in a carbon monoxide containing atmosphere. The chemical reactions took place at ambient temperature and pressure conditions. The complexes were rapidly transported in a gas stream to collection setups or gas phase chromatography devices. The physisorption of the complexes on $\mathrm{Au}$ and $\mathrm{SiO}_{2}$ surfaces
\end{abstract}

\footnotetext{
*Corresponding author: Julia Even, Helmholtz-Institut Mainz, 55099 Mainz, Germany; and Johannes Gutenberg-Universität Mainz, 55099 Mainz, Germany, e-mail: j.even@gsi.de

Alexander Yakushev, Willy Hartmann, Egon Jäger, Birgit Kindler, Jörg Krier, Bettina Lommel, Matthias Schädel, Brigitta Schausten: GSI Helmholtzzentrum für Schwerionenforschung GmbH, 64192 Darmstadt, Germany

Christoph Emanuel Düllmann: Johannes Gutenberg-Universität Mainz, 55099 Mainz, Germany; and Helmholtz-Institut Mainz, 55099 Mainz, Germany; and GSI Helmholtzzentrum für Schwerionenforschung GmbH, 64192 Darmstadt, Germany

Jan Dvorak: Helmholtz-Institut Mainz, 55099 Mainz, Germany Robert Eichler, Andreas Türler, David Wittwer: Paul Scherrer Institut, 5232 Villigen, Switzerland; and University of Bern, 3012 Bern, Switzerland

Jadambaa Khuyagbaatar: Helmholtz-Institut Mainz, 55099 Mainz, Germany; and GSI Helmholtzzentrum für Schwerionenforschung GmbH, 64192 Darmstadt, Germany

Oliver Gothe, Heino Nitsche: Lawrence Berkeley National Laboratory, Berkeley, CA 94720, USA

Daniel Hild, Jens Volker Kratz, Lorenz Niewisch, Inna Pysmenetska: Johannes Gutenberg-Universität Mainz, 55099 Mainz, Germany Norbert Wiehl: Johannes Gutenberg-Universität Mainz, 55099 Mainz, Germany; and Helmholtz-Institut Mainz, 55099 Mainz, Germany
}

was studied. We also studied the stability of some of the complexes, showing that these start to decompose at temperatures above $300^{\circ} \mathrm{C}$ in contact with a quartz surface. Our studies lay a basis for the investigation of such complexes with transactinides.

Keywords: Carbonyl Complexes, Short-lived Isotopes, Carbonyl Synthesis, In-Situ Synthesis, Adsorption Studies, Thermochromatography, Isothermal Chromatography, Thermal Stability, Fission Products, Superheavy Elements, Physical Preseparation.

DOI 10.1515/ ract-2013-2198

Received October 9, 2013; accepted June 13, 2014

\section{Introduction}

Experimental studies of the heaviest elements are very challenging due to low production rates and generally short half-lives. Gas-phase chemical reactions have proven powerful for such studies as they often proceed quickly and with high yield. To date, thermally stable, simple inorganic compounds with the transactinide present in a high oxidation state, such as halides, oxyhalides, hydroxides, or oxides, have been studied [1-4]. Due to experimental limitations, it was not possible to synthezise less stable compounds, e.g., organometallic ones [5].

As a first step towards the investigation of complexes of the transactinides in oxidation state " 0 ", we have chosen to focus on metal carbonyl complexes. More than 100 years ago, Mond reported the first synthesis of a carbonyl complex - nickel tetracarbonyl [6]. From that time on, metal-carbonyl chemistry was developed and became an important topic in basic research and in the applied sciences; see, e.g., [7]. Stable, binary, mononuclear, neutral, volatile metal carbonyl complexes are only known 
with vanadium, nickel, group 6, and group 8 elements [8]. Mononuclear binary carbonyl complexes of palladium, platinum, and group-11 elements were synthesized and studied in matrix isolation experiments [9, 10]. Multinuclear (like the dimetal decacarbonyl complexes of group 5 elements, the tetrametal dodecacarbonyl complexes of cobalt and iridum, or the octarhodium hexadecacarbonyl complexes) or mixed carbonyl complexes with ligands like nitrosyl, hydrogen or oxygen are known for transition metals of almost all groups.

Carbon monoxide is a very strong ligand, a good $\sigma$ donor and $\pi$-acceptor, and carbonyl complexes are in the focus of many theoretical studies; see, e.g., [11-15]. The dominant interactions in the bonding between the transition metal and the ligand are i) the interaction of the Highest Occupied Molecular Orbital (HOMO) of the CO molecule with an empty $\sigma$-symmetric atomic orbital of the metal and ii) the interaction between occupied $\pi$-type $d$ orbitals of the metal and the $2 \pi^{*}$ orbital (Lowest Unoccupied Molecular Orbital, LUMO) of CO. The $\sigma$-donor bond strengthens the $\mathrm{C}-\mathrm{O}$ bond. The $\pi$-backbonding, on the other hand, weakens the $\mathrm{C}-\mathrm{O}$ bond, as electron density is donated to the antibonding LUMO [11].

Chemical properties of the transactinide elements are strongly influenced by relativistic effects. Their influence scales approximately proportionally to $Z^{2}[1,16]$. Theoretical predictions suggest the carbon-metal bond in the seaborgium hexacarbonyl complex to be influenced by these effects. Due to the relativistic contraction of the $p_{1 / 2}$ and $s$ orbitals, the $\sigma$-donation bonding is predicted to become slightly weaker in carbonyl complexes of transactinide elements than in their lighter homologs [15].

Due to the indirect relativistic effect the $\pi$-symmetric $d$ orbitals are more delocalised. This strengthens the $\pi$ backbonding in the $\mathrm{Sg}-\mathrm{CO}$ bond compared to that in the lighter homologs [15].

The synthesis of carbonyl complexes with shortlived isotopes appeared challenging so far. With a few exceptions, metal carbonyl complexes are formed under high carbon monoxide pressure conditions (around 300 bar) [8].

Despite these limitations, hot atom chemistry with carbonyl complexes has been investigated as well [17-19]. Mixtures of chromium hexacarbonyl with ${ }^{235} \mathrm{U}$ were irradiated with neutrons. Molybdenum as fission product was found to have replace chromium in these complexes. Subsequently, the molybdenum hexacarbonyl could be evaporated $[17,18]$. In other experiments, tungsten was produced in a nuclear fusion reaction and stopped in a chromium hexacarbonyl catcher, from which it could be evaporated as tungsten hexacarbonyl [19]. These methods

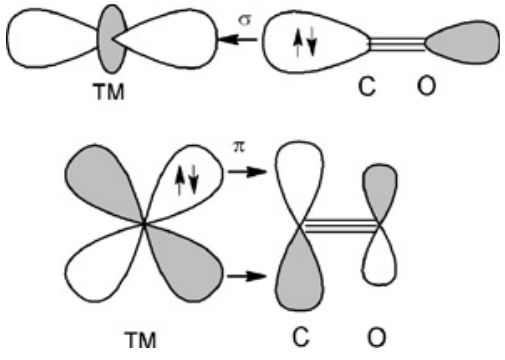

Fig. 1: Schematic drawing (after Ref. [11]) of the $\sigma$-donation bond (upper picture) from the HOMO of the carbonyl ligand to the atomic orbitals of the transition metal (TM) in $\sigma$-symmetry, and $\pi$-backdonation bond (bottom) from the d-orbital of the transition metal to the LUMO of the carbonyl ligand.

are discontinuous and time consuming and thus restricted to studies of at least moderately long-lived isotopes.

The transactinide elements can only be produced in nuclear fusion reactions with low cross-sections, which allow for production rates from a few atoms per minute down to single atoms per month. Furthermore, their halflives are - with a few exceptions - in the range of milliseconds to about a minute. Therefore, chemical experiments with these elements are conducted under atom-at-a-time conditions, and continuous procedures are preferred.

In the past, no studies were performed to investigate whether a high pressure of more than one hundred bar is necessary to synthesise metal carbonyl complexes in chemical reactions with single, recoiling ions or atoms thermalized in a carbon-monoxide containing atmosphere.

Only recently, we reported on the successful in-situ synthesis of carbonyl complexes with short-lived molybdenum, tungsten, and osmium isotopes [20]. In this work, we give a complete and more detailed overview on our studies involving also technetium, ruthenium, rhodium, iridium and rhenium, which open the door for studies of carbonyl complexes also with superheavy elements.

Fission products were directly thermalized in carbonmonoxide containing gas-mixtures. In the experiments with fusion products, the approach of physical preseparation [5, 21, 22] was used. These experiments were conducted at the TransActinide Separator and Chemistry Apparatus TASCA at the GSI Helmholtz Centre for Heavy Ion Research in Darmstadt, Germany (GSI) [23]. Within TASCA, the evaporation residues were separated in the magnetic field of a dipole magnet from the primary beam. They were then focused by quadrupole magnets to the TASCA focal plane. There, the evaporation residues exited the separator through a thin vacuum window and entered a gas-filled volume ( $\sim$ bar) called Recoil Transfer Cham- 
ber (RTC), in which they were thermalized [24]. The main advantages of this technique - compared to more traditional approaches, where EVRs are thermalized in a recoil chamber mounted directly behind the target - are the reduced nuclear background and the absence of a beam induced plasma and heat in the RTC. This allows using (organic) molecular reagents for in-situ syntheses of fragile molecules inside the RTC [25].

We investigated the formation of transition metal carbonyl complexes, their adsorption on silicon dioxide and gold surfaces as well as their thermal stability on a hot quartz surface.

\section{Experimental}

To explore whether an in-situ synthesis of transition metal carbonyl complexes is feasible, the $4 d$ elements molybdenum, technetium, ruthenium, and rhodium were produced in neutron induced fission at the TRIGA Mainz research reactor. $\mathrm{A}{ }^{249} \mathrm{Cf}$-target was irradiated with thermal neutrons and the recoiling fission products were thermalized in a nitrogen/carbon monoxide gas mixture. Volatile compounds were transported in the gas stream to collection or chemistry devices.

The $5 d$ elements tungsten, rhenium, osmium, and iridium were synthesised in ${ }^{24} \mathrm{Mg}$-induced nuclear fusion reactions at TASCA. The evaporation residues were thermalized in a helium/carbon monoxide mixture in the RTC. The transport of various refractory $d$ elements in carbon-monoxide containing gas mixtures was investigated. The adsorption behaviour of in-situ synthesized carbonyl complexes was studied in various experiments either by isothermal chromatography or by thermochromatography. Their thermal stability was investigated in a decomposition setup by passing the volatile species over a hot quartz surface.

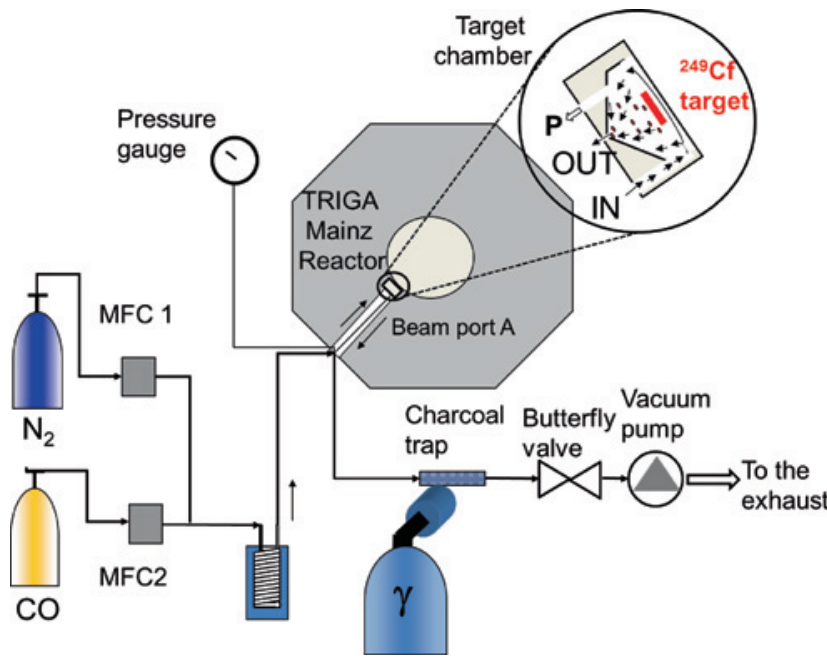

Fig. 2: Schematic of the "once through" gas-flow system used at the reactor. The target chamber was placed at beam port A near the reactor core and flushed (IN) through a circular allocator to the outlet (OUT) in the center of the funnel shaped chamber cover. The chamber was connected with a tube $(\mathrm{P})$ to a pressure gauge. The chamber was flushed with pure $\mathrm{N}_{2}$ or with a $\mathrm{N}_{2} / \mathrm{CO}$ mixture. The ratio of $\mathrm{CO}$ to $\mathrm{N}_{2}$ as well as the total gas flow rate were regulated by the mass flow controllers MFC1 and MFC2 (MKS, Type 1179). Prior to entering the target chamber, the gas passed through a copper coil placed in a dry ice-ethanol bath to remove moisture. Subsequently, the gas flew through a tube with $7 \mathrm{~mm}$ inner diameter into the target chamber. From there, the gas and the volatile compounds exited through a capillary and passed a charcoal trap, which was placed in front of a HPGe $\gamma$-detector. From there, the gas passed a butterfly valve and the vacuum pump and was vented into the exhaust. A pressure gauge (pressure control, MKS, model 627D) was connected to the target chamber to monitor the pressure inside the target chamber. Based on the measured pressure, the butterfly valve in front of the vacuum pump was actuated to maintain a constant pressure in the chamber by regulating the pumping capacity.

Table 1: Overview of the fusion reactions.

\begin{tabular}{llrrl}
\hline $\begin{array}{l}\text { Energy from } \\
\text { UNILAC/ } \\
\mathrm{MeV} / \mathbf{u}\end{array}$ & $\begin{array}{l}\text { Target } \\
\text { material }\end{array}$ & $\begin{array}{r}\text { Average } \\
\text { Target thick- } \\
\text { ness } / \boldsymbol{\mu g} / \mathbf{c m}^{2}\end{array}$ & $\begin{array}{r}\text { Lab-frame energy } \\
\text { in the centre } \\
\text { of target/MeV }\end{array}$ & $\begin{array}{l}\text { Nuclear } \\
\text { reaction }\end{array}$ \\
\hline 6.5 & ${ }^{144} \mathrm{Sm}(88.6 \%$ enriched $)$ & $\sim 380$ & 145 & ${ }^{144} \mathrm{Sm}\left({ }^{44} \mathrm{Mg}, 4-5 n\right){ }^{163-164} \mathrm{~W}$ \\
5.5 & ${ }^{144} \mathrm{Sm}(88.6 \%$ enriched $)$ & $\sim 380$ & 126 & ${ }^{144} \mathrm{Sm}\left({ }^{24} \mathrm{Mg}, 3-4 n\right){ }^{164-165} \mathrm{~W}$ \\
6.5 & ${ }^{152} \mathrm{Gd}_{2} \mathrm{O}_{3}(39.3 \%$ enriched $)$ & $\sim 734$ & 144 & ${ }^{152} \mathrm{Gd}\left({ }^{24} \mathrm{Mg}, 5-6 n\right){ }^{170-171} \mathrm{O}$ \\
5.5 & ${ }^{152} \mathrm{Gd}_{2} \mathrm{O}_{3}(39.3 \%$ enriched $)$ & $\sim 734$ & 125 & ${ }^{152} \mathrm{Gd}\left({ }^{24} \mathrm{Mg}, 4 n\right){ }^{172} \mathrm{Os}$ \\
5.5 & ${ }^{n a t} \mathrm{~Tb}_{2} \mathrm{O}_{3}$ & $\sim 310 / \sim 650$ & 126 & $\left.{ }^{159} \mathrm{~Tb}\left({ }^{24} \mathrm{Mg}, 4-5 n\right)\right)^{178-179} \mathrm{Ir}$ \\
5.5 & ${ }^{n a t} \mathrm{Eu}_{2} \mathrm{O}_{3}$ & $\sim 450$ & 126 & ${ }^{n a t} \mathrm{Eu}\left({ }^{24} \mathrm{Mg}, x n\right){ }^{170-172} \mathrm{Re}$ \\
\hline
\end{tabular}

The energy loss of the beam in matter was calculated with SRIM2008 [27]. 


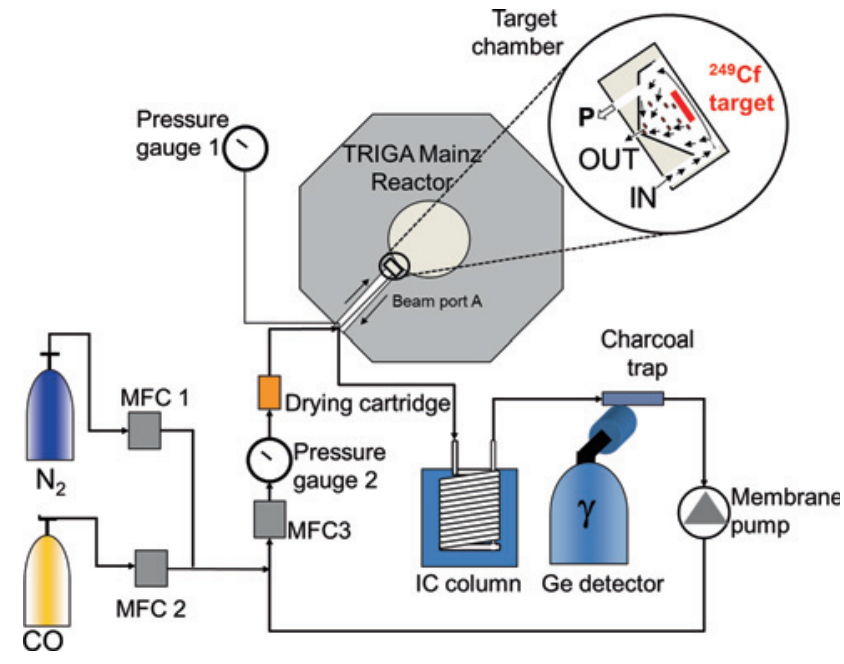

Fig. 3: Schematic of the gas loop system used at the TRIGA reactor. The target chamber with the ${ }^{249} \mathrm{Cf}$ target was placed near the reactor core. The gas was pre-dried by passing through cartridges filled with a molecular sieve (not shown). By opening the mass flow controllers MFC1 and MFC2, the loop was filled with gas. Mass flow controller MFC3 regulated the flow rate in the loop. The membrane pump ensured a constant flow. The pressure inside the loop was monitored with pressure gauge 2 . The gas inside the loop was dried by passing through a drying cartridge filled with Sicapent ${ }^{\mathrm{TM}}$. Then it passed through a tube to the target chamber. All volatile compounds were transported in the gas stream out of the chamber to a charcoal trap, which was monitored with a HPGe $\gamma$ detector. For the isothermal chromatography (IC) studies, a quartz spiral (IC column) kept in a cooling bath was installed between the target chamber and the charcoal trap.

\subsection{Production of the radioactive isotopes}

\subsection{1 $4 d$ elements at TRIGA Mainz}

Short-lived isotopes of the $4 d$ transition metals were produced by thermal-neutron induced fission of ${ }^{249} \mathrm{Cf}$ at the TRIGA Mainz research reactor, see Figures 2 and 3. A $350 \mu \mathrm{g}{ }^{249} \mathrm{Cf}$-target covered with a $15-\mu \mathrm{m}$ thick aluminium foil was placed at beam port A close to the reactor core. The thermal neutron flux at the target position was $9.8 \times 10^{10} \mathrm{n} /\left(\mathrm{cm}^{2} \mathrm{~s}\right)$. The cover foil was used to suppress of the fission products of the heavy mass branch, which have shorter ranges in matter than those of the light mass branch. Due to extensive previous use, the cover foil was partially perforated, allowing a fraction of the heavier products to pass through.

\subsection{2 $5 d$ elements at TASCA}

Short-lived isotopes of the $5 d$ elements tungsten, rhenium, osmium, and iridium, were synthesized in ${ }^{24} \mathrm{Mg}$-induced nuclear fusion reactions at the UNIversal Linear ACcelerator (UNILAC) at GSI. Beam energies of $6.5 \mathrm{MeV} / \mathrm{u}$ and $5.5 \mathrm{MeV} / \mathrm{u}$ from the UNILAC were used, with typical beam intensities being $10^{12}$ ions/s.

Three banana-shaped targets sputtered on $2-\mu \mathrm{m}$ thick Ti-foils were mounted onto a target wheel of ARTESIA type [26]. The target-wheel rotation was synchronized with the macropulse structure of the UNILAC (beam pulse frequency: $50 \mathrm{~Hz}$, macropulse duration: $5 \mathrm{~ms}$ ) such that each 5 -ms long macropulse was spread out over one target. Table 1 gives an overview of the average target thicknesses and nuclear reactions.

Based on their differing magnetic rigidities, evaporation residues exiting the target were separated from the primary beam and unwanted nuclear reaction products in the gas-filled TransActinide Separator and Chemistry Apparatus TASCA $[23,28]$.

TASCA was operated in the Small Image Mode [23]. The evaporation residues were thermalized in the RTC designed for the small image mode $[24,29]$. The RTC was separated from TASCA by a 3.3- $\mu$ m thick MYLAR foil window, which was supported by a honeycomb grid. The size of the RTC window was $(3 \times 4) \mathrm{cm}^{2}$. To determine the rate of incoming alpha-decaying evaporation residues, a retractable Si detector suited for the registration of implanting ions and of alpha-particles emitted by previously implanted nuclei could be placed behind the RTC window. The RTC chamber was cylindrical with an inner diameter of $3 \mathrm{~cm}$ and a depth of $2 \mathrm{~cm}$. For the chemistry experiments, the gas entered from two inlets at the sides, $1 \mathrm{~cm}$ behind the RTC window. The gas outlet was funnel-shaped and located in the rear plate of the chamber.

\subsection{Gases and chemicals}

In the experiments at the TRIGA Mainz research reactor, nitrogen (purity >99.998\%; $<5 \mathrm{ppm} \mathrm{O}_{2},<5 \mathrm{ppm}_{2} \mathrm{O}$, $<1$ ppm $\mathrm{C}_{\mathrm{n}} \mathrm{H}_{\mathrm{m}}$ ) from Westfalen Gas was used as transport gas. As reactive gas, carbon monoxide (Westfalen Gas, purity $>99 \%,<10000$ ppm $\mathrm{O}_{2}+\mathrm{N}_{2}+\mathrm{Ar}+\mathrm{H}_{2}$ ) and (Westfalen Gas, purity $99.97 \%,<250$ ppm $\mathrm{O}_{2}+\mathrm{N}_{2}+\mathrm{Ar}$; $<10$ ppm $\mathrm{H}_{2}$, $<5$ ppm $\mathrm{H}_{2} \mathrm{O}$ ) was used.

At the TASCA separator, helium from Linde (purity $>99.9999 \%, \leq 0.5 \mathrm{ppm} \mathrm{O}_{2}$; $\leq 0.5 \mathrm{ppm} \mathrm{N}$, $\leq 0.5 \mathrm{ppm}$ $\mathrm{H}_{2} \mathrm{O}, \leq 0.5$ ppm $\mathrm{H}_{2}, \leq 0.1$ ppm $\mathrm{C}_{\mathrm{m}} \mathrm{H}_{\mathrm{n}} ; \leq 0.1 \mathrm{ppm} \mathrm{CO}$ and $\leq 0.2$ ppm $\mathrm{CO}_{2}$ ) and carbon monoxide from Linde (purity 
$>99.9 \%$; $\leq 60 \mathrm{ppm} \mathrm{Ar}+\mathrm{O}_{2}$; $\leq 750 \mathrm{ppm} \mathrm{N}_{2}, \leq 250 \mathrm{ppm} \mathrm{H}$, $\leq 50 \mathrm{ppm} \mathrm{C}_{\mathrm{m}} \mathrm{H}_{\mathrm{n}}$ ) were used.

\subsection{Gas jet system}

\subsubsection{The gas jet at the TRIGA Mainz reactor}

At the TRIGA Mainz, the ${ }^{249} \mathrm{Cf}$-target was placed in a cylindrical chamber with a funnel-shaped cover; see Figures 2 and 3. The gas entered through a circular allocator at the bottom of the chamber and exited through an outlet in the center of the funnel shaped top. This way, the chamber was flushed very efficiently.

Two different gas systems were used - a "oncethrough" system in which all tubes were made of polyethylene (PE) for measuring the transport yields, and a loop system, in which the gas was circulated through tubes made of perfluoroalkoxy Teflon (PFA). The "once-through" gas flow system is schematically shown in Figure 2.

Three different ways to transport fission products were studied using the "once-through" system: (i) the transport of volatile fission products in pure nitrogen, (ii) the transport of volatile compounds in a nitrogen/carbonmonoxide mixture, and (iii) the non-chemically selective transport of all fission products with a $\mathrm{KCl}$ cluster jet. For the cluster transport, the nitrogen passed a tube furnace, which contained potassium chloride kept at $640{ }^{\circ} \mathrm{C}$, before entering the target chamber. In this way, $\mathrm{KCl}$ clusters (aerosol particles) were formed and were transported in the gas stream to the target chamber. Non-volatile fission products attached to the aerosol particles and were transported out of the target chamber. To avoid aerosol contamination in the experiments with a pure nitrogen jet or a nitrogen/carbon-monoxide jet, the experiments with $\mathrm{KCl}$ clusters were performed at the end of the experimental campaigns after finishing the other gas jet studies.

The gas loop (see Figure 3) was used to provide very dry experimental conditions in the isothermal chromatography and decomposition experiments. The isothermal chromatography setup is described in section 2.5 and the decomposition setup in section 2.6.

The loop was evacuated by a vacuum pump (not shown in Figure 2) and was filled with a gas mixture through two mass flow controllers (MFC1 and MFC2). In the gas loop, a stable gas flow was provided by an additional mass flow controller (MFC3) and a membrane pump. The pressure inside the loop was monitored. In case of a pressure decrease below a preset value, the loop was filled through MFC1 and MFC2. The gas in the loop passed a drying cartridge filled with Sicapent ${ }^{\mathrm{TM}}$ (granu-

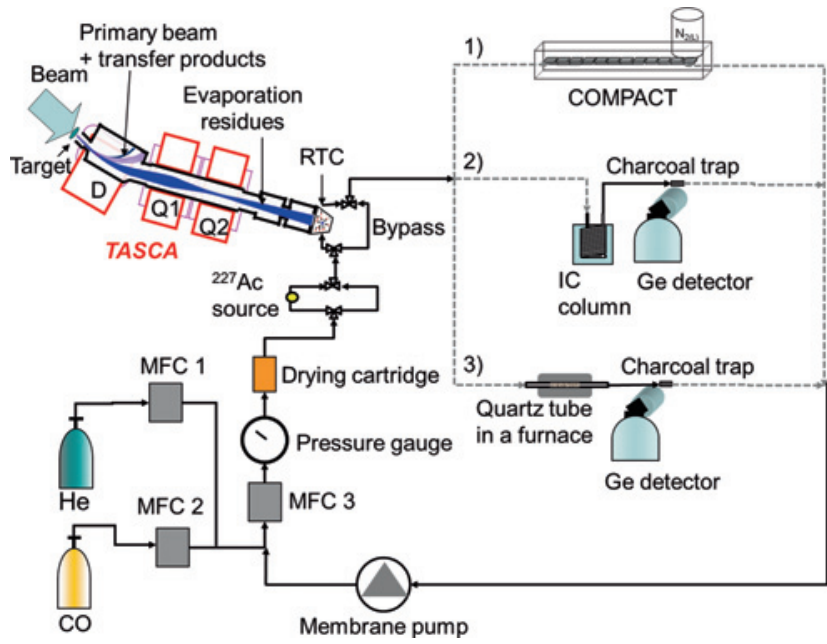

Fig. 4: Schematic of the gas loop system used at TASCA. Three different setups could be installed in the loop -1) COMPACT for thermochromatography studies with $\alpha$-decaying isotopes, 2) an isothermal chromatography (IC) column followed by a charcoal trap for IC experiments, and 3) a quartz tube placed in a furnace followed by a charcoal trap for decomposition studies. The loop was filled by opening the mass flow controllers MFC1 and MFC2. Mass flow controller MFC3 regulated the flow rate in the loop. The membrane pump ensured a constant flow. A pressure gauge monitored the pressure in the loop. The gas inside the loop was dried by passing a drying cartridge filled either with Sicapent ${ }^{\mathrm{TM}}$ or molecular sieve cooled by liquid nitrogen. For calibration of COMPACT, the gas could be guided through a ${ }^{227}$ Ac-source emanating ${ }^{219} \mathrm{Rn}$. The gas passed the RTC at the end of TASCA. There, the recoiling ions were thermalized and volatile species were transported to the connected experimental setup.

lated phosphorous pentoxide on a zeolith carrier) drying agent. By continuous circulation, the gas was dried. During the decomposition studies (see section 2.6.), the gas first passed a cartridge filled with activated charcoal to remove organic impurities and afterwards a cartridge filled with Sicapent ${ }^{\mathrm{TM}}$ for drying. All volatile compounds, which were transported from the target chamber out of the reactor, were collected on charcoal traps; see section 2.4.

\subsubsection{Gas jet system at TASCA}

The gas loop system, which was used at TASCA, is schematically shown in Figure 4. Either of three different experimental setups were installed in the gas loop: i) the COMPACT detector array for thermochromatography studies [30, 31] (see section 2.8), ii) an isothermal chromatography setup (IC) (see section 2.6), or iii) a decomposition setup (see section 2.7).

The gas loop system was connected to a vacuum pump (not shown in Figure 4) to evacuate the system before fill- 
ing with gas. All gases were pre-dried by passing a cartridge filled with molecular sieve. The gas-loop was filled and the gas mixture was regulated by the mass flow controllers MFC1 and MFC2. The mass flow controller MFC3 regulated the flow rate inside the loop. To provide a stable gas flow inside the loop, a membrane pump was installed.

To dry the gas in the loop, a cooling trap filled with molecular sieve placed in liquid nitrogen was installed in the experiments with the COMPACT. In the isothermal chromatography and decomposition experiments, this cooling trap was replaced by a cartridge filled with Sicapent ${ }^{\mathrm{TM}}$. A pressure gauge was installed in the loop and was connected to the same control device as the mass flow controllers. In case of a pressure drop below a pre-set value, the loop was automatically filled through the mass flow controllers MFC1 and MFC2. The gas passed through the RTC. If the pressure inside the loop reached values outside of pre-set limits, the RTC was automatically disconnected by two valves and the gas was released through a bypass for safety reasons.

All tubes were made of stainless steel or PFA. In experiments with COMPACT, the connection between the RTC and COMPACT was a $1.5-\mathrm{m}$ long PFA capillary with an inner diameter of $4 \mathrm{~mm}$. For energy calibration of the COMPACT detector array, the gas was guided over a ${ }^{227} \mathrm{Ac}$ emanation source. ${ }^{219} \mathrm{Rn}\left(t_{1 / 2}=3.19 \mathrm{~s}\right)$, a decay product of ${ }^{227} \mathrm{Ac}$ was transported within the gas-stream. The $\alpha$-decay of ${ }^{219} \mathrm{Rn}$ and its non-volatile daughter nuclides ${ }^{211} \mathrm{Po}$ and ${ }^{211} \mathrm{Bi}$ allowed an on-line calibration of the COMPACT detector array.

For the isothermal chromatography and the decomposition experiments, the gas loop was extended. The RTC and the chemistry device were connected by a 10-m long polytetrafluoroethylene Teflon (PTFE) capillary with an inner diameter of $2 \mathrm{~mm}$. The gas passed either the IC or the decomposition setup. Volatile compounds that passed these devices were collected on a charcoal trap monitored by a HPGe $\gamma$-detector.

\subsection{Charcoal traps}

For collecting the volatile compounds activated charcoal traps (ACC traps) were used in the experiments at the TRIGA Mainz reactor and in the experiments with shortlived iridium and rhenium isotopes at TASCA. The charcoal traps were made of $5-\mathrm{cm}$ long tubes (i.d. $=4 \mathrm{~mm}$ ) filled with $c a .100 \mathrm{mg}$ activated charcoal (ACC, 20-40 mesh). The charcoal was fixed in the tube by two quartz wool plugs. To monitor the transport of volatile compounds, the traps were placed in front of a HPGe $\gamma$-detector.

\subsection{Isothermal chromatography}

For adsorption studies, a spiral-shaped quartz tube was connected to the gas loop. The quartz tube had an inner diameter of $2 \mathrm{~mm}$ and was placed over a length of $191 \mathrm{~cm}$ in a cooling bath, the temperature of which was varied for the different measurements. An ACC trap was placed behind the spiral and monitored by a HPGe $\gamma$-detector.

\subsection{Decomposition setup}

In the experiments aiming at studying the thermal stability of the carbonyl complexes, a quartz tube placed in a tube furnace was installed in the gas loop. In the middle of the quartz tube, a quartz wool plug was inserted, which provided an efficient surface contact of the gas to the quartz. The temperature of the quartz wool was varied between room temperature and $600^{\circ} \mathrm{C}$. The transport yield achieved through the quartz tube was determined for different temperatures. An ACC trap was placed behind the quartz tube and monitored by a HPGe $\gamma$-detector.

\subsection{Cryo Online Multidetector for Physics And Chemistry of Transactinides - COMPACT}

The experiments with $\alpha$-particle emitting isotopes were performed with the COMPACT detector array [30, 31]. Two different COMPACT detector arrays were used: one with a $\mathrm{SiO}_{2}$ surface (COMPACT $\mathrm{SiO}_{2}$ ), the other one with a gold surface (COMPACT Au). A detailed description and technical details of COMPACT are given in [30, 31]. A COMPACT array consists of two Invar ${ }^{\mathrm{TM}}$ panels. On each panel, 32 Positive Intrinsic Negative (PIN) diodes of $(1 \times 1) \mathrm{cm}^{2}$ are mounted, forming a $32-\mathrm{cm}$ long, $1-\mathrm{cm}$ wide detector array. The active detection surface of each PIN diode in COMPACT $\mathrm{SiO}_{2}$ is $(9.3 \times 9.3) \mathrm{mm}^{2}$. In COMPACT Au, the active detection surface of the PIN diodes is $(9.7 \times 9.9) \mathrm{mm}^{2}$ or $(9.7 \times 9.7) \mathrm{mm}^{2}$. Two panels are assembled such that the active surfaces of PIN diodes face each other at a distance of $0.6 \mathrm{~mm}$. With this detector assembly, a detectionefficiency for registering $\alpha$ particles emitted from species inside the channel of $76 \%$ is reached. The gas and volatile species contained in it pass through this channel and the volatile compounds interact with the detector surfaces.

The detector channel is placed in a vacuum box made of steel covered with nickel. The downstream end of the detector panel is contacted by a copper cold finger, which is cooled with liquid nitrogen. This way, a temperature gradi- 
ent is established along the chromatography column. Temperatures are monitored with type $\mathrm{K}$ thermocouples. At the COMPACT $\mathrm{SiO}_{2}$ detector array, four thermocouples are mounted along the array at equal distances. At the COMPACT Au detector array, three sensors are mounted, one at each end of the array and one in the center.

\section{Results}

\subsection{Transported fission products and their relative transport yields}

At the experiments at the TRIGA Mainz reactor, the transported fission products were identified by their gamma lines. Three different types of transport were analysed with fission products and compared with each other - transport in pure nitrogen, transport with a classical $\mathrm{KCl}$ cluster jet, and transport in a carbon monoxide/nitrogen mixture.

In pure nitrogen only volatile products like xenon, iodine and selenium as well as their daughter isotopes were identified, see Figure 5.

With a $\mathrm{KCl}$ cluster jet, non-volatile fission products are transported with transport yields of $60 \%-70 \%$ [32] and no chemical selectivity. A typical spectrum is shown in Figure 6.

Also with the carbon monoxide jet a transport of volatile fission products as well as of most of the $4 d$ elements was observed. Non-volatile elements of the main

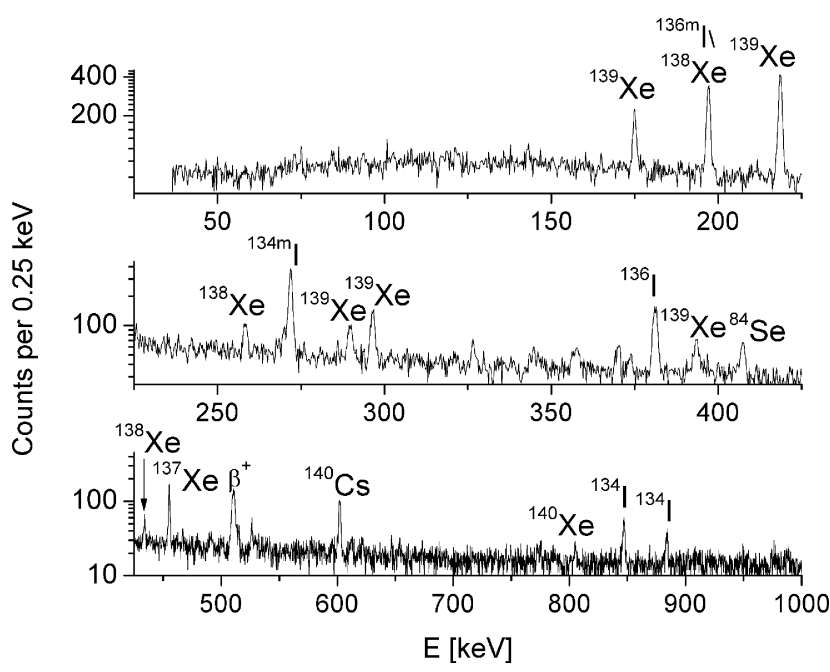

Fig. 5: Spectrum of fission products transported in a $500 \mathrm{~mL} / \mathrm{min}$ nitrogen stream and collected on a charcoal trap. The sample was collected for $2 \mathrm{~min}$ and was subsequently measured for $2 \mathrm{~min}$.

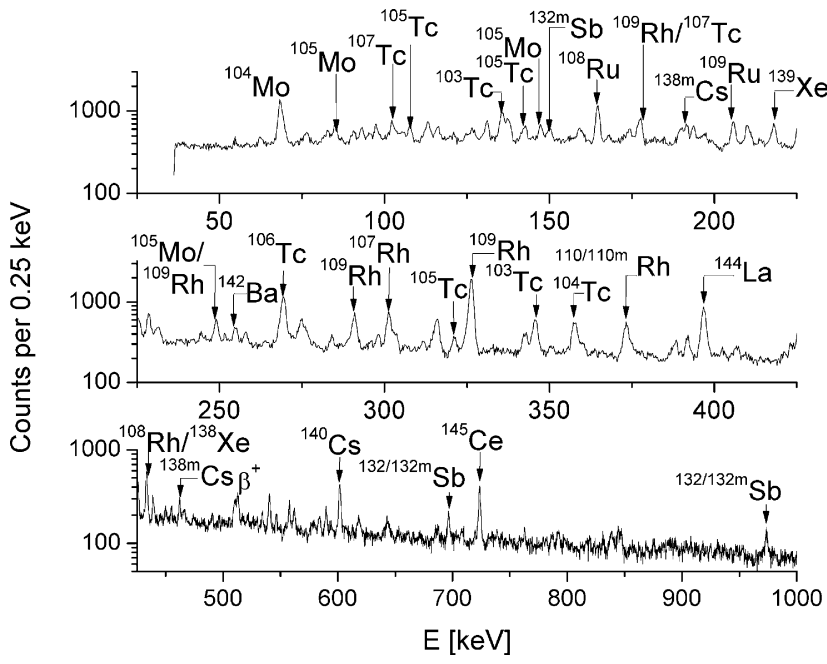

Fig. 6: Spectrum of fission products transported with a $\mathrm{KCl}$ cluster jet $(500 \mathrm{~mL} / \mathrm{min}$ nitrogen, saturated with $\mathrm{KCl}$ particles), and collected on a charcoal filter. The sample was collected for $2 \mathrm{~min}$ and was measured subsequently for $2 \mathrm{~min}$. Some of the most intense $\gamma$ lines are labelled.

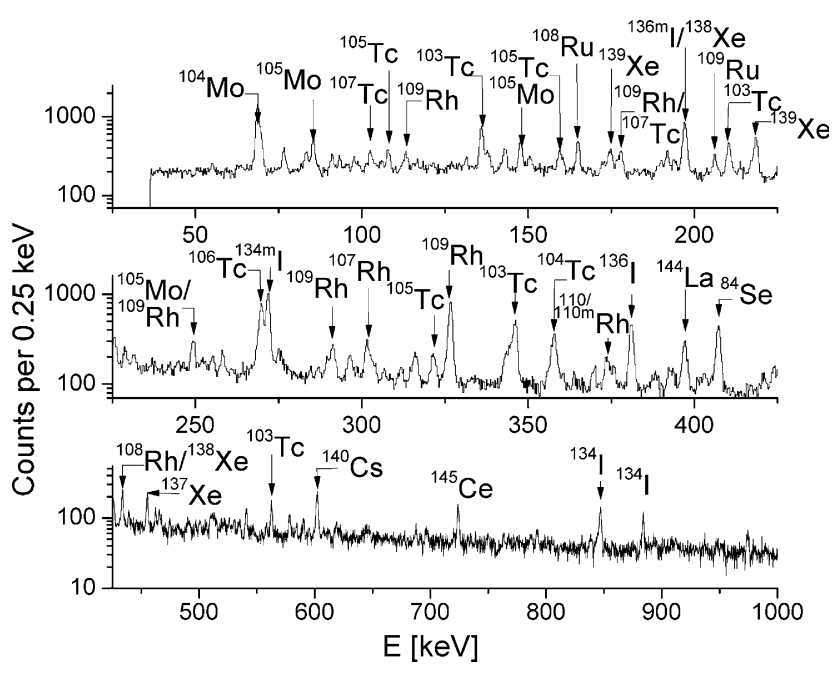

Fig. 7: Spectrum of fission products transported in a mixture of $350 \mathrm{~mL} / \mathrm{min}$ carbon monoxide and $150 \mathrm{~mL} / \mathrm{min}$ nitrogen, and collected on a charcoal filter. The sample was collected for $2 \mathrm{~min}$ and measured subsequently for $2 \mathrm{~min}$.

groups (such as e.g. Sb, Ba, and Cs) were not transported in the nitrogen/carbon monoxide mixture, see Figure 7.

The data show clearly $\gamma$ lines of $d$ elements. We explain this as transport in the form of volatile compounds of these elements with carbon monoxide. The transport yield of selenium increases significantly, if carbon monoxide is added to the transport gas. This effect appears due to the formation of volatile carbonyl selenide, which was observed before under comparable conditions [33, 34]. 
In case of the $d$ elements, the assignment of any observed $\gamma$ line to a specific element being the transported one is not as trivial as it might appear at first glance. In nuclear fission, several isobars are generally produced as primary fission products, which subsequently undergo $\beta^{-}$. decay until a stable end-product is reached. A $\gamma$ line of a certain isotope being present in the spectra is thus only indicative of the decay of this isotope on the filter. Whether the transport from the recoil chamber to the filter took place in the form of a volatile species of this isotope, or in the form of a volatile species of one of its $\beta^{-}$-decay precursors (or as a superposition of both possibilities) requires a more detailed analysis.

To facilitate this discussion, we present in Figure 8 the relevant part of the chart of nuclides, where we show for each isotope (i) the cumulative fission yield, and (ii) what fraction is produced directly in the fission process (as opposed to production via $\beta^{-}$-decay from the precursor).

\section{Molybdenum:}

Several isotopes of molybdenum $\left({ }^{101} \mathrm{Mo}-{ }^{106} \mathrm{Mo}\right)$ were clearly identified in the spectra of different collection and measurement cycles. Typical measurement cycles were: collecting a sample for two minutes and measuring afterwards for six minutes in three $2 \mathrm{~min}$ intervals. Other samples were collected for ten minutes and measured afterwards for $50 \mathrm{~min}$ in five $10 \mathrm{~min}$ intervals. ${ }^{101} \mathrm{Mo}$ and ${ }^{102} \mathrm{Mo}$ are mainly formed in the decay of ${ }^{101} \mathrm{Nb}$ and ${ }^{102} \mathrm{Nb}$; see Figure 8. The relative transport yields for ${ }^{101} \mathrm{Mo}$ in a 1:1 nitrogen/carbon monoxide mixture compared to a $\mathrm{KCl}$ cluster jet was less than $10 \% .{ }^{104} \mathrm{Mo}-{ }^{106} \mathrm{Mo}$ are dominantly produced directly $\left({ }^{104} \mathrm{Mo}: 77 \%,{ }^{105} \mathrm{Mo}: 87 \%\right.$, ${ }^{106}$ Mo: $94 \%$ ), see Figure 8 . The influence of precursor ef-

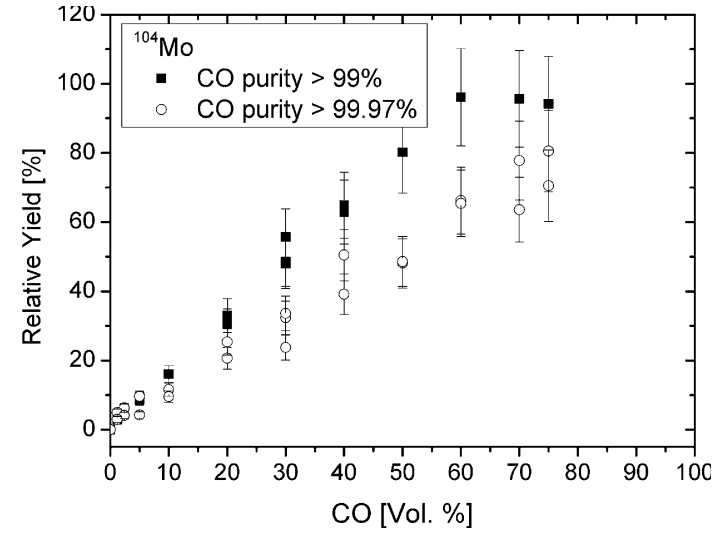

Fig. 9: The transport yield of ${ }^{104} \mathrm{Mo}$ produced in the nuclear reaction ${ }^{249} \mathrm{Cf}(n, f)$ in a carbon monoxide/nitrogen gas mixture, normalized to the yield with a $\mathrm{KCl}$ cluster jet depending on the carbon monoxide fraction. The total gas flow rate was $500 \mathrm{~mL} / \mathrm{min}$. Open circles: samples collected with carbon monoxide purity $>99.97 \%$. Full squares: samples taken with CO purity $>99 \%$.

fects is thus small, if not negligible, at least in case of ${ }^{106} \mathrm{Mo}$. We thus conclude that transport occurred indeed for Mo, in the form of a volatile carbonyl complex. The transport yield of ${ }^{104} \mathrm{Mo}$ was quantitatively analysed by comparison with the spectra taken with the $\mathrm{KCl}$ cluster jet, see Figure 9. Relative transport yields of more than $80 \%$ were observed at carbon monoxide fractions of $60 \%$ and higher.

The half-lives of ${ }^{102} \mathrm{Mo}$ and ${ }^{101}$ Mo are significantly longer than those of the heavier molybdenum isotopes. One would expect higher transport yields of ${ }^{102} \mathrm{Mo}$ and ${ }^{101}$ Mo than for the short-lived isotopes, which decay to a more appreciable amount during the transport. However, the relative transport yields in a carbon monoxide jet of the long-lived isotopes, which are mainly formed in the $\beta$-decay of niobium isotopes, are much lower than the

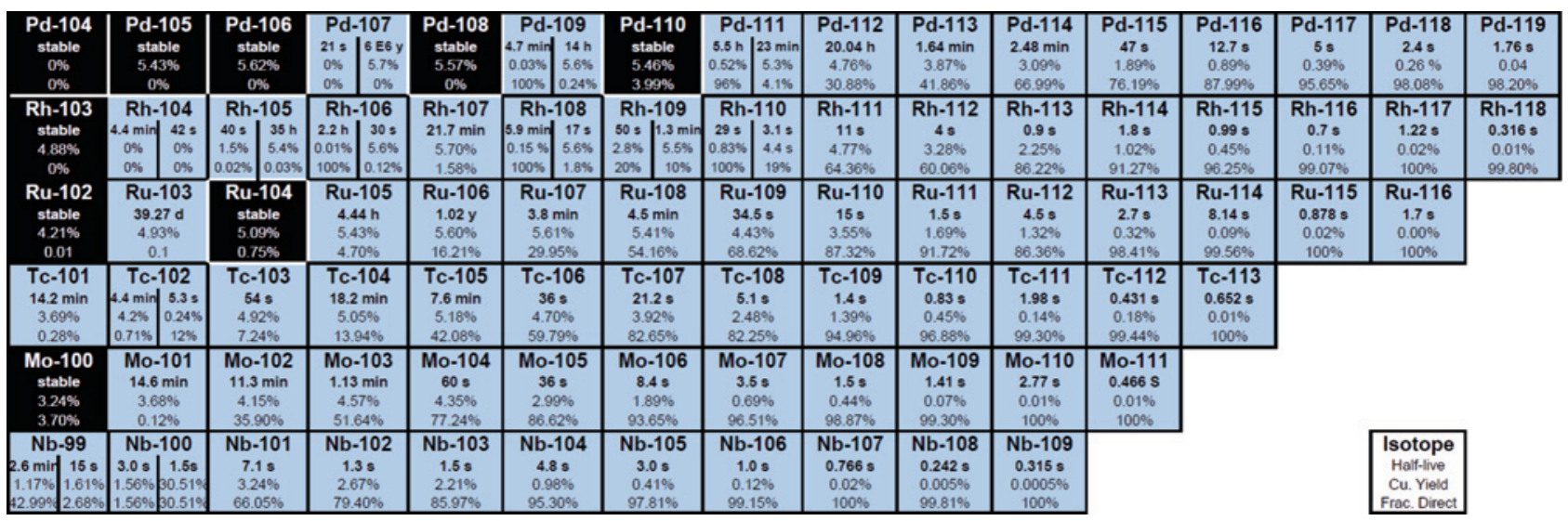

Fig. 8: Cut-out of the nuclear chart. For every shown isotope the half-life, the cumulative fission yields as well as the fraction, which is produced as a primary fission product, are given in the format as indicated in the box in the lower right. Data are taken from [35]. 


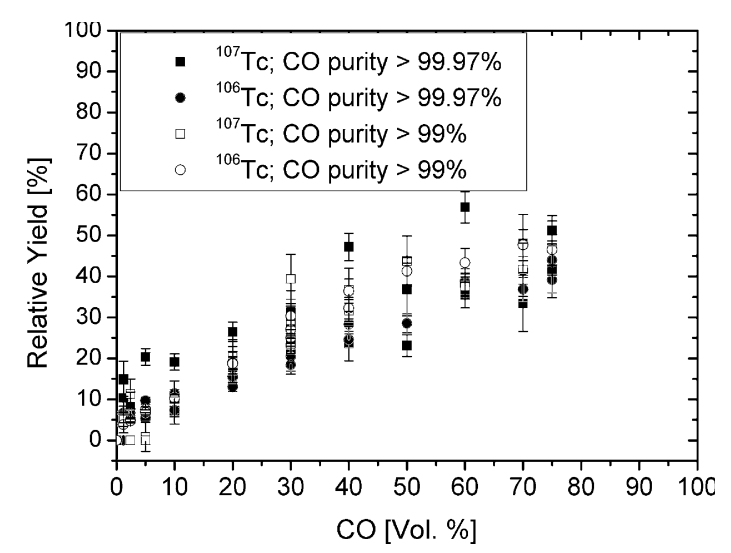

Fig. 10: Transport yield of Tc with $500 \mathrm{~mL} / \mathrm{min}$ total gas flow rate as a function of the carbon monoxide fraction.

transport yields of the more short-lived isotopes, which are formed predominantly as primary fission products. Mainly primary fission products seem to form a volatile complex. This leads to the assumption that for the chemical reaction, the molybdenum atom needs to be in or pass through the gas phase as it is the case in the thermalization process of the primary fission products.

\section{Technetium:}

Technetium isotopes were clearly identified in the samples using the ${ }^{249} \mathrm{Cf}(n, f)$ reaction. Figure 10 shows the relative transport yields for ${ }^{106} \mathrm{Tc}$ and ${ }^{107} \mathrm{Tc}$.

At high carbon monoxide concentration, the transport yield relative to a $\mathrm{N}_{2} \mathrm{KCl}$ jet was around $40 \%$. In the case of technetium, precursor effects play a much more significant role than in the case of molybdenum. ${ }^{107} \mathrm{Tc}\left(t_{1 / 2}=21.2 \mathrm{~s}\right)$ is mainly formed directly in the fission process, see Figure 8. The transport time from the target chamber to the detector is longer than the half-life of the $\beta$-decay precursor ${ }^{107} \mathrm{Mo}$. Therefore, we consider transport exclusively in the form of a volatile molybdenum species as unlikely and conclude that technetium forms volatile compounds with carbon monoxide and can be transported in a carbon monoxide jet.

\section{Ruthenium:}

${ }^{107} \mathrm{Ru}$ and ${ }^{108} \mathrm{Ru}$ were identified in the spectra. Only $30 \%$ of ${ }^{107} \mathrm{Ru}$ and $54 \%$ of ${ }^{108} \mathrm{Ru}$ are directly formed in the fission process, see Figure 8. Furthermore the transport yields are much lower for ruthenium isotopes (see Figure 11) than for molybdenum and technetium isotopes. Therefore, the

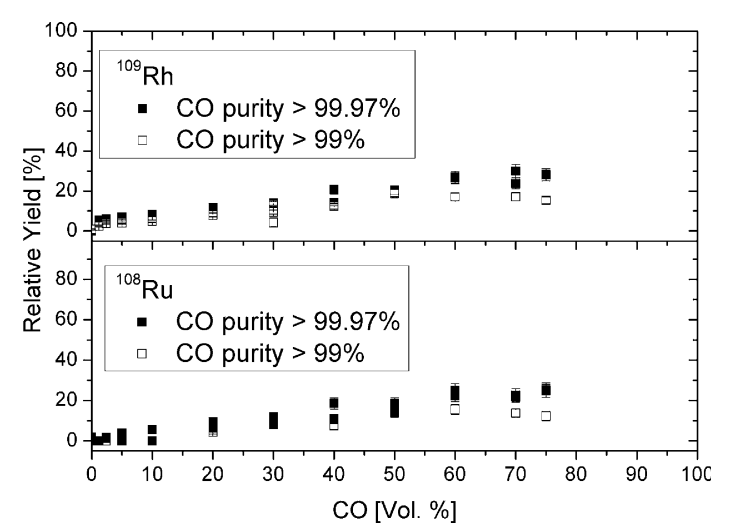

Fig. 11: Upper panel: transport yield of ${ }^{109} \mathrm{Rh}$ relative to a $\mathrm{KCl}$ cluster jet. Lower panel: transport yield of ${ }^{108} \mathrm{Ru}$ relative to a $\mathrm{KCl}$ cluster jet.

data do not allow a final conclusion if only the technetium precursor was the transported species or if also ruthenium could be transported with the carbon monoxide jet.

\section{Rhodium:}

Rhodium was produced in the fission of ${ }^{249} \mathrm{Cf}$. The isotopes ${ }^{107} \mathrm{Rh},{ }^{108} \mathrm{Rh},{ }^{109} \mathrm{Rh}$, and ${ }^{110,110 \mathrm{~m}} \mathrm{Rh}$ were identified in the experiments at a total flow rate of $500 \mathrm{~mL} / \mathrm{min}$. These isotopes are mainly formed in the decay of ruthenium isotopes, see Figure 8. From the data it is hard to distinguish, whether ruthenium or rhodium was the transported species, or even the precursor technetium isotopes. The transport yields for ${ }^{108} \mathrm{Ru}$ and ${ }^{109} \mathrm{Rh}$ were very similar, see Figure 11.

\subsection{Transported $5 d$ elements synthesized in heavy-ion fusion reactions}

In the measurements at TASCA, $\beta^{+} / \mathrm{EC}$-and $\alpha$-decaying isotopes of $5 d$ elements were produced in fusion neutronevaporation reactions. Hence, feeding by precursors is excluded.

\section{Tungsten:}

Short-lived tungsten isotopes were identified in the COMPACT detector by their $\alpha$-decay energies. In the experiments at a beam energy of $6.5 \mathrm{MeV} / \mathrm{u}$, two $\alpha$ lines were observed in the spectra. The line at $5.15 \mathrm{MeV}$ was assigned to ${ }^{164} \mathrm{~W}\left(t_{1 / 2}=6 \mathrm{~s}\right)$ and the one at $5.38 \mathrm{MeV}$ to ${ }^{163} \mathrm{~W}\left(t_{1 / 2}=2.75 \mathrm{~s}\right)$. After the change of the beam energy to 
$5.5 \mathrm{MeV} / \mathrm{u}$ only the single $\alpha$ line of ${ }^{164} \mathrm{~W}$ at $5.15 \mathrm{MeV}$ was observed in the spectra. The measurements show clearly that the short-lived isotopes, which were thermalized in the RTC, form volatile compounds with carbon monoxide. The distribution in the COMPACT detector shows a clear chromatography peak (see Figure 13), therefore cluster transport can be excluded. The COMPACT measurements were compared to a measurement performed with a Si detector placed behind the RTC window. Depending on the gas flow rates and the pressure, transport yields of around $30 \%$ for ${ }^{164} \mathrm{~W}$ were achieved.

\section{Rhenium:}

Gamma-ray emitting isotopes of rhenium were studied as none of the isotopes accessible in the ${ }^{24} \mathrm{Mg}+{ }^{\text {nat }} \mathrm{Eu}$ fusion reaction have suitable $\alpha$-branches. The short-lived ${ }^{170} \mathrm{Re}$ $\left(t_{1 / 2}=9.2 \mathrm{~s}\right),{ }^{171} \operatorname{Re}\left(t_{1 / 2}=15.2 \mathrm{~s}\right)$ and ${ }^{172,172 \mathrm{~m}} \operatorname{Re}\left(t_{1 / 2}=15 \mathrm{~s}\right.$ and $55 \mathrm{~s}$ ) could be identified by their $\gamma$ lines. Precursor effects can be excluded. The adsorption of this volatile compound on a quartz surface at low temperatures was studied, as well as the decomposition on a hot quartz surface. These observations indicated unambiguously that volatile complexes of rhenium with carbon monoxide were formed.

\section{Osmium:}

Short-lived osmium isotopes were identified in COMPACT measurements. In the experiments at a beam energy of $6.5 \mathrm{MeV} / \mathrm{u}$, an $\alpha$ line at $5.4 \mathrm{MeV}$ was observed and assigned to ${ }^{170} \mathrm{Os}\left(t_{1 / 2}=7.3 \mathrm{~s}\right)$. At $5.5 \mathrm{MeV} / \mathrm{u}$, an $\alpha$ line at $5.15 \mathrm{MeV}$ was observed and assigned to ${ }^{172} \mathrm{Os}\left(t_{1 / 2}=\right.$ $19.2 \mathrm{~s})$. We conclude that the recoiling osmium forms volatile compounds with the $\mathrm{CO}$ in the RTC, as published in [20].

\section{Iridium:}

Similarly to the case of rhenium, only $\gamma$-emitting isotopes of iridium were accessible. The isotopes ${ }^{178} \operatorname{Ir}\left(t_{1 / 2}=12 \mathrm{~s}\right)$ and ${ }^{179} \operatorname{Ir}\left(t_{1 / 2}=79 \mathrm{~s}\right)$ were unambiguously identified by $\gamma$ spectroscopy. Precursor effects can again be excluded. Thus, it is shown that also iridium forms volatile carbonyl complexes, which can be transported in the gas stream over several meters.

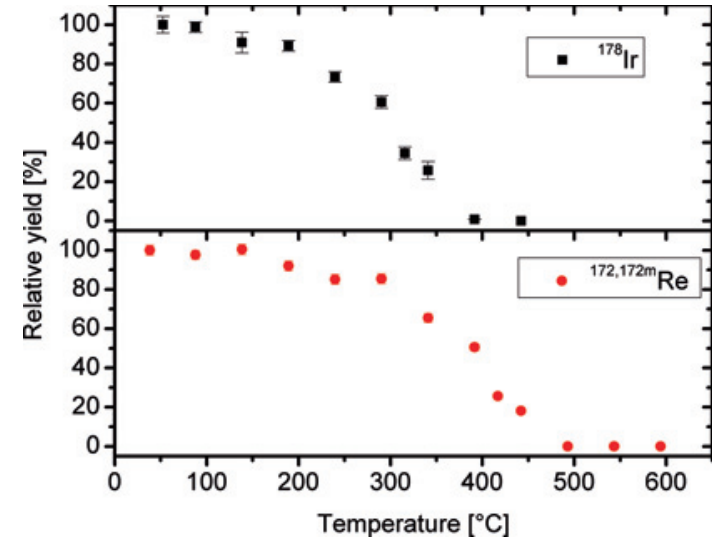

Fig. 12: Relative yield measured in the ACC trap as a function of the temperature of the quartz wool plug in the decomposition setup. Upper panel: relative yields of ${ }^{178} \mathrm{Ir}$. The data were normalized to the value obtained at $52^{\circ} \mathrm{C}$. Lower panel: relative yield observed for ${ }^{172,172 \mathrm{~m}} \mathrm{Re}$. The data were normalized to the value obtained at $38^{\circ} \mathrm{C}$.

\subsection{Decomposition of the carbonyl complexes}

To study the thermal stabilities of rhenium and iridium carbonyl complexes, a gas stream with a gas flow rate of $0.54 \mathrm{~L} / \mathrm{min}$ of a $4: 1$ (volume ratio) mixture of He and $\mathrm{CO}$ was guided from the RTC through the decomposition setup. Figure 12 shows the temperature dependence of the transport yield behind the decomposition setup. At $390{ }^{\circ} \mathrm{C}, 50 \%$ of the rhenium carbonyl complexes were destroyed. As $50 \%$ of the iridium carbonyl complexes decomposed at $300^{\circ} \mathrm{C}$, we conclude that the iridium complex is thermally less stable than the rhenium complex.

\subsection{Adsorption of the carbonyl complexes}

The adsorption of the carbonyl complexes was studied with thermochromatography and with isothermal chromatography. All chromatograms were compared to Monte Carlo simulations to gain information on the adsorption enthalpies, $-\Delta H_{\mathrm{ads}}$, of the complexes on the chromatography column surface. This method has been suggested by Zvara [36] and is well established [3]. Details on the used simulation program are explained in [37]. The input data are given in the Supplementary material of this publication. 


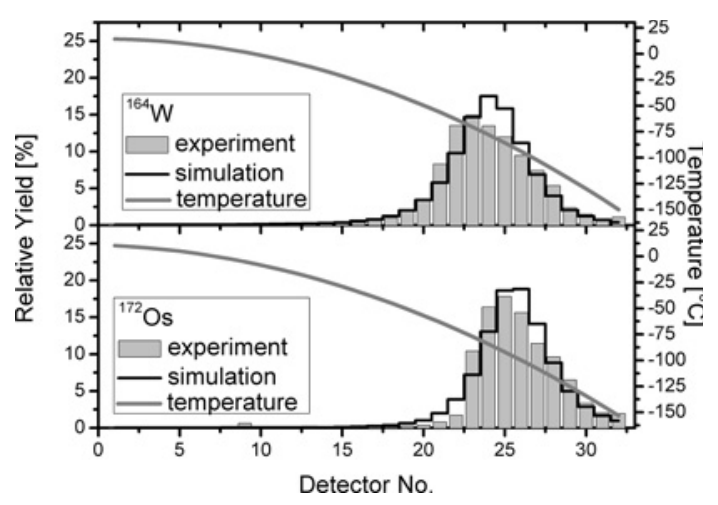

Fig. 13: Thermochromatograms measured with the COMPACT with a gold surface. The gas-mixture was $50 \% \mathrm{He}$ and $50 \% \mathrm{CO}$. The total gas flow rate was $0.73 \mathrm{~L} / \mathrm{min}$. The pressure inside the RTC was 0.8 bar. Lower graph: thermochromatogram of ${ }^{172} \mathrm{Os}(\mathrm{CO})_{5}$. Upper graph: thermochromatogram of ${ }^{164} \mathrm{~W}(\mathrm{CO})_{6}$. Grey solid lines: temperature gradient (right-hand $y$-axis). Grey bars: relative yields per detector pair (left-hand y-axis). Blacklines: results of Monte Carlo simulations (left-hand y-axis).

\subsubsection{COMPACT measurements}

The adsorption of tungsten hexacarbonyl and osmium pentacarbonyl on $\mathrm{SiO}_{2}$ and gold surfaces was studied in measurements with COMPACT. The adsorption studies in COMPACT $\mathrm{SiO}_{2}$ were already reported in [20], where also arguments for the assignement to the two mentioned chemical compounds were given (see also Section 4.1). The $-\Delta H_{\text {ads }}$ on $\mathrm{SiO}_{2}$ surfaces for tungsten hexacarbonyl is $(46.5 \pm 2.5) \mathrm{kJ} / \mathrm{mol}$, and a deposition temperature of $(-42 \pm 10){ }^{\circ} \mathrm{C}$ was measured for ${ }^{164} \mathrm{~W}$ at a gas flow rate of $0.85 \mathrm{~L} / \mathrm{min}$ (see Figure 4 in [20]). For osmium pentacarbonyl, the $-\Delta H_{\text {ads }}$ is $\left(43.5_{-2.5}^{+3.5}\right) \mathrm{kJ} / \mathrm{mol}$. The $-\Delta H_{\text {ads }}$ values are indicative of physisorption processes on the $\mathrm{SiO}_{2}$ surface.

The adsorption behaviour on gold was studied with the COMPACT Au detector array. Figure 13 shows the deposition pattern of tungsten and osmium in the COMPACT Au detector array. The maximum deposition yield for $\mathrm{W}(\mathrm{CO})_{6}$ was found at $\left(-70_{-20}^{+10}\right)^{\circ} \mathrm{C}$ at a gas flow rate of $0.73 \mathrm{~L} / \mathrm{min}$. The $-\Delta H_{\text {ads }}$ of tungsten hexacarbonyl on gold is $\left(41_{-4}^{+3}\right) \mathrm{kJ} / \mathrm{mol}$, and the $-\Delta H_{\text {ads }}$ of osmium pentacarbonyl on gold is ( $39 \pm 4 \mathrm{~kJ} / \mathrm{mol}$ ).

\subsubsection{Isothermal chromatography studies}

Isothermal chromatography was applied to investigate the interaction of the volatile compounds of molybdenum, technetium, ruthenium, rhodium, rhenium, and iridium with a quartz surface. The carbonyl complexes of the fis-

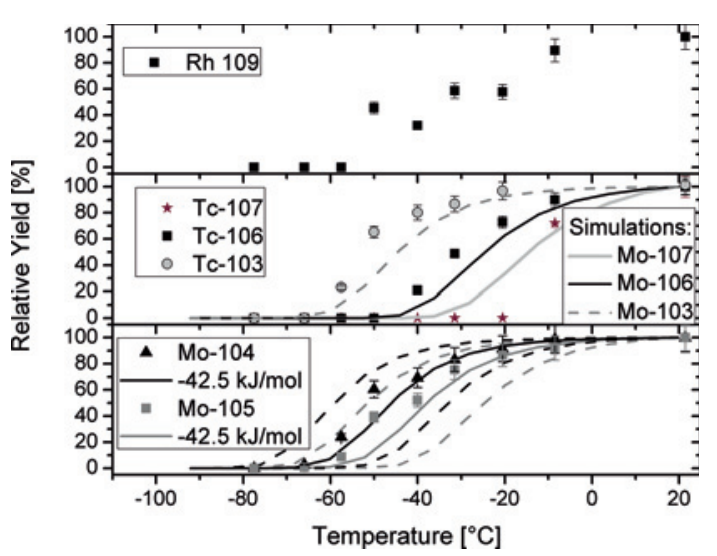

Fig. 14: Break-through curves of fission product carbonyl complexes. The gas flow rate was $600 \mathrm{~mL} / \mathrm{min}$ and the pressure in the target chamber was 1315 mbar. For an individual measurement, the chromatography column was kept at a constant temperature and flushed with the transport gas. The charcoal trap was measured for $15 \mathrm{~min}$ (real time, areas corrected for the dead time of the system). Subsequently, the temperature was changed and after a $15 \mathrm{~min}$ break suitable for isotopes of the previous measurement to decay before the start of a next experiment, the trap was measured again. All displayed yields are normalized to those obtained at room temperature. Bottom panel: break-through curves of ${ }^{104} \mathrm{Mo}$ $\left(t_{1 / 2}=60 \mathrm{~s}\right)$ and ${ }^{105} \mathrm{Mo}\left(t_{1 / 2}=35.6 \mathrm{~s}\right)$. Symbols: experimental data. The solid lines are the results of the Monte Carlo simulations with $-\Delta H_{\mathrm{ads}}=42.5 \mathrm{~kJ} / \mathrm{mol}$. Dashed lines: error limits of $\pm 2.5 \mathrm{~kJ} / \mathrm{mol}$. Middle Panel: Break-through curves of ${ }^{103} \mathrm{Tc}\left(t_{1 / 2}=54.2 \mathrm{~s}\right),{ }^{106} \mathrm{Tc}$ $\left(t_{1 / 2}=35.6 \mathrm{~s}\right)$, and ${ }^{107} \mathrm{Tc}\left(t_{1 / 2}=21.2 \mathrm{~s}\right)$. The lines show the simulations for the mother isotopes ${ }^{103} \mathrm{Mo},{ }^{106} \mathrm{Mo}$, and ${ }^{107} \mathrm{Mo}$ with $-\Delta H_{\text {ads }}=42.5 \mathrm{~kJ} / \mathrm{mol}$. Top panel: Break-through curves of ${ }^{109} \mathrm{Rh}$ $\left(t_{1 / 2}=80 \mathrm{~s}\right)$.

sion products of ${ }^{249} \mathrm{Cf}$ and of short-lived iridium and rhenium isotopes produced at TASCA passed through a quartz column.

Figure 14 shows the break-through curves for molybdenum, technetium, and rhodium isotopes. Precursor effects influence some of the results, especially in the case of ${ }^{103} \mathrm{Tc},{ }^{106} \mathrm{Tc},{ }^{109} \mathrm{Rh}$. Hence, we restrict the quantitative discussion to the Mo isotopes, where precursor effects are negligible, see Figure 8.

At a gas flow rate of $600 \mathrm{~mL} / \mathrm{min}$, the temperature at which $50 \%$ of the species of interest decay inside the chromatography column, $T_{50 \%}$, was $(-46 \pm 10)^{\circ} \mathrm{C}$ for ${ }^{104} \mathrm{Mo}(\mathrm{CO})_{6}\left(t_{1 / 2}=60 \mathrm{~s}\right)$ and $(-41 \pm 10){ }^{\circ} \mathrm{C}$ for ${ }^{105} \mathrm{Mo}(\mathrm{CO})_{6}$ $\left(t_{1 / 2}=35.6 \mathrm{~s}\right)$. The $-\Delta H_{\text {ads }}$ of molybdenum hexacarbonyl on quartz was determined to be $(42.5 \pm 2.5) \mathrm{kJ} / \mathrm{mol}$. Figure 14, bottom panel, shows the isothermal chromatogram of ${ }^{105} \mathrm{Mo}$ and ${ }^{104} \mathrm{Mo}$. The solid lines show the result of the simulation assuming $-\Delta H_{\mathrm{ads}}=42.5 \mathrm{~kJ} / \mathrm{mol}$, and the dashed lines depict the error limits of $\pm 2.5 \mathrm{~kJ} / \mathrm{mol}$.

The apparent $T_{50 \%}$ values for the different technetium isotopes were $(-51 \pm 10){ }^{\circ} \mathrm{C}$ for ${ }^{103} \mathrm{Tc}\left(t_{1 / 2}=54.2 \mathrm{~s}\right)$, 


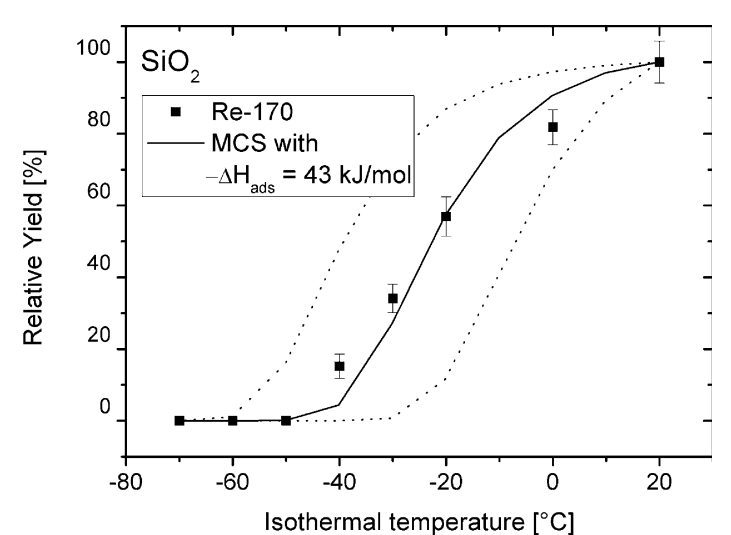

Fig. 15: Isothermal chromatogram measured with ${ }^{170} \operatorname{Re}\left(t_{1 / 2}=9.2 \mathrm{~s}\right)$. The gas mixture was He:CO $4: 1$. The gas flow rate was $0.54 \mathrm{~L} / \mathrm{min}$. Black symbols: measured values normalized to the measurement at $20{ }^{\circ} \mathrm{C}$. Solid lines: result of a Monte Carlo simulation MCS with $-\Delta H_{\mathrm{ads}}=43 \mathrm{~kJ} / \mathrm{mol}$, Dashed lines: uncertainty limits of $\pm 3 \mathrm{~kJ} / \mathrm{mol}$.

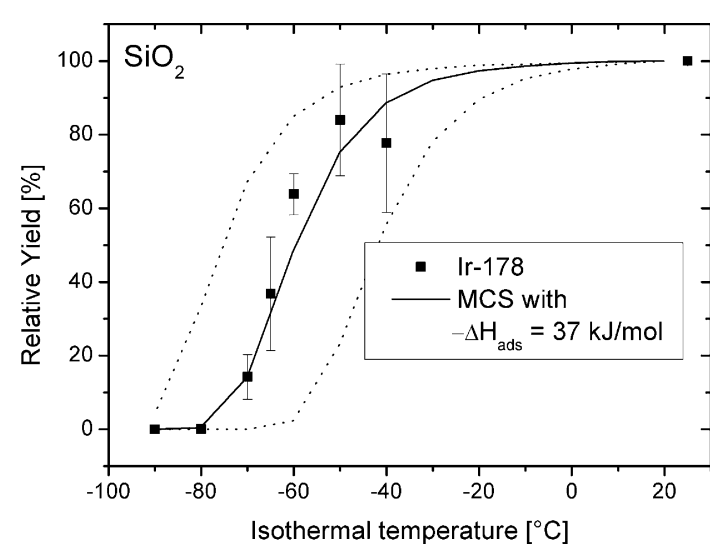

Fig. 16: Isothermal chromatogram measured with ${ }^{178} \operatorname{Ir}\left(t_{1 / 2}=12 \mathrm{~s}\right)$. The gas mixture was $4: 1 \mathrm{He}: \mathrm{CO}$. The gas flow rate was $0.54 \mathrm{~L} / \mathrm{min}$. Black symbols: experimental data normalized to the measurement at $25^{\circ} \mathrm{C}$. Solid line: result of a Monte Carlo simulation with

$-\Delta H_{\mathrm{ads}}=37 \mathrm{~kJ} / \mathrm{mol}$. Dashed lines: uncertainty limits of $\pm 3 \mathrm{~kJ} / \mathrm{mol}$.

$(-30 \pm 10){ }^{\circ} \mathrm{C}$ for ${ }^{106} \mathrm{Tc}\left(t_{1 / 2}=35.6 \mathrm{~s}\right)$, and $(-17 \pm 10){ }^{\circ} \mathrm{C}$ for ${ }^{107} \mathrm{Tc}\left(t_{1 / 2}=21.2 \mathrm{~s}\right)$. These isotopes are fed to differing extent by the transport and decay of their molybdenum precursors. Assuming transport exclusively in the form of the precursors (and using $-\Delta H_{\mathrm{ads}}=42.5 \mathrm{~kJ} / \mathrm{mol}$ ), breakthrough curves as depicted by the lines in the middle panel in Figure 14 would result. Within the accuracy of our measurements, a definite answer on the volatility of technetium compounds is not possible. A quantitative analysis of adsorption enthalpies of the measured isothermal chromatograms of ${ }^{103} \mathrm{Tc},{ }^{106} \mathrm{Tc}$, and ${ }^{107} \mathrm{Tc}$ is not possible as the technetium isotopes originate from the decay of molybdenum isotopes. Nevertheless the deposition curves at low temperatures indicate physisorption processes on quartz.
The upper graph of Figure 14 shows the isothermal chromatogram of ${ }^{109} \mathrm{Rh}$. The apparent $T_{50 \%}$ temperature of ${ }^{109} \mathrm{Rh}\left(t_{1 / 2}=80 \mathrm{~s}\right)$ was $(-35 \pm 17){ }^{\circ} \mathrm{C}$. As ${ }^{109} \mathrm{Rh}$ is mainly formed in the decay of ${ }^{109} \mathrm{Ru}$ (see Figure 8), a quantitative analysis of the adsorption enthalpy is not possible.

In the experiments at TASCA, iridium and rhenium isotopes were studied with isothermal chromatography. In these experiments, the interpretation of the data is not affected by precursor effects. In Figures 15 and 16, the breakthrough curves for ${ }^{170} \mathrm{Re}$ and ${ }^{178} \mathrm{Ir}$ are shown.

Adsorption enthalpies on $\mathrm{SiO}_{2}$ of $-\Delta H_{\mathrm{ads}}=$ $(43 \pm 3) \mathrm{kJ} / \mathrm{mol}$ for the rhenium complex and $-\Delta H_{\mathrm{ads}}=$ $(37 \pm 3) \mathrm{kJ} / \mathrm{mol}$ for the iridium complex were deduced. Respecting that the experiments were performed under identical conditions, the iridium complex appears to be slightly more volatile than the rhenium one.

\section{Discussion}

\subsection{Elements volatilized through thermalization in $\mathrm{CO}$ media}

At the TRIGA Mainz reactor, it could be demonstrated that several refractory fission products convert into volatile chemical species upon thermalization in carbon monoxide-containing gas at ambient pressure and temperature. We conclude that volatile carbonyl compounds were in situ formed inside the target chamber.

A similar behaviour was previously observed only for short-lived selenium isotopes [33, 34], which forms selenium carbonyl, SeCO. This is a structural analog of carbon dioxide.

\section{Group 6}

From the transport yield measurements of molybdenum isotopes follows that mainly primary fission products form the volatile complexes. The free metal atoms or ions in the gas phase directly react with the carbon monoxide. If an atom collides with the wall of the chamber before the formation of a neutral carbonyl complex, it is adsorbed and "lost" for a chemical reaction.

While direct speciation of the formed species is not possible with current analytical techniques because of the small number of molecules present, only plausibility arguments given below allow an interpretation of the results.

For the group 6 elements, we propose that in our experiments $\mathrm{Mo}(\mathrm{CO})_{6}$ and $\mathrm{W}(\mathrm{CO})_{6}$ were formed. Mononu- 
clear hexacarbonyl complexes of group 6 elements are well known, see, e.g., $[13,38]$. They fulfil the 18 electron rule, are thus rather stable, and are known to be volatile at room temperature. Physisorption of these hexacarbonyl complexes at low temperature $\left(-100^{\circ} \mathrm{C}\right)$ has been reported [39]. These studies agree with our results.

\section{Group 7}

For group 7 elements, no stable, neutral, mononuclear, binary carbonyl complex is known to our knowledge. Only from observations in Szilard-Chalmers reaction studies, the formations of a technetium pentacarbonyl [40] and rhenium pentacarbonyl complex [41] were postulated. Well known, stable binary carbonyl complexes of these elements, which have so far been observed, are multinuclear ones. The most common ones are dimetal decacarbonyl complexes like $\mathrm{Tc}_{2}(\mathrm{CO})_{10}$ and $\mathrm{Re}_{2}(\mathrm{CO})_{10}$ [42], which are known to be volatile. However, respecting the extremely small number of technetium and rhenium atoms present in our experiment (a few thousand per second) the formation of dinuclear complexes can be excluded. Still, the "breakthrough curves" in the isothermal chromatography measurements indicate a transport in the form of a specific chemical compound. Note that in case of cluster transport, the relative yield would be rather independent of the column temperature, or at least the $T_{50 \%}$ values would be identical for all technetium and rhenium isotopes. This, however, is not the case (see Figure 14, middle panel, and Figure 15). Furthermore, our data show the volatile rhenium species to decompose at a certain temperature, which again supports the assignment to a transport of a specific chemical compound.

A mononuclear, binary carbonyl complex of an element of group 7 would be a radical type complex, which would be quite reactive. Possibly, thermodynamically stable mononuclear species exist, but in experiments with macroscopic amounts of technetium or rhenium, the formation of more stable polynuclear species prevails. The question about the exact nature of the transported species is currently open and deserves further experimental and theoretical studies. We cannot fully rule out, however, that complexes with heteroligands formed in our experiments.

Reference [42] gives an overview on volatile technetium carbonyl complexes. Complexes of the type $\mathrm{Tc}(\mathrm{CO})_{5} \mathrm{X}$ with ligands like NO, $\mathrm{H}$ or halides are known to be volatile. The carbonyl chemistry of rhenium is similar to that of technetium. Several mixed carbonyl complexes of the type $\operatorname{Re}(\mathrm{CO})_{5} \mathrm{X}$ are known.
We propose that rhenium and technetium likely form radical type carbonyl complexes, but respect that possibly mixed carbonyl complexes were observed in our experiments.

\section{Group 8}

From the measurements at the TRIGA reactor, we cannot conclude with certainty the transport of ruthenium in the form of a volatile carbonyl complex. The studies of the heavier homolog osmium, however, were not disturbed by precursor effects and unambiguously show that osmium forms volatile complexes. The most likely interpretation is that ruthenium and osmium formed pentacarbonyl complexes [20]. These are volatile complexes [8], which are known to be stable [43].

\section{Group 9}

Similarly as for group 7, also for rhodium and iridium, no binary mononuclear carbonyl complexes are known. We again exclude transport in a form other than as a specific chemical compound in our experiments, based on the same arguments as given above for the group 7.

The lightest member of group 9, cobalt, is known to form cobalt tetracarbonyl, a radical type complex produced by evaporating dicobalt octacarbonyl below room temperature [44]. For rhodium and iridium only mixed polynuclear carbonyl complexes are known, see. e.g. [8, 45, 46]. Due to atom-at-a-time conditions in our experiments, the formation of polynuclear complexes is excluded. We consider the formation of mononuclear tetracarbonyl complexes most likely, but cannot exclude the formation of mixed carbonyl complexes with trace impurities present in the used gases formed. Note that for rhodium, precursor effects cannot be excluded.

\subsection{Thermal stability of carbonyl complexes}

For the group 6, 8, and 10 neutral binary carbonyl complexes, the first dissociation energies of the metal-CO bond are known from literature [43]. Within the groups the dissociation energies are the highest for the $3 d$ elements, and are lowest for $4 d$ elements. In each period, the complexes of group 6 have the highest dissociation energy. Beyond group 6 , the dissociation energies decrease with increasing group number. 
In our studies, which were limited to rhenium and iridium complexes, the rhenium ones appear to be more stable than the iridium ones assuming the same decomposition path. $50 \%$ of the rhenium complexes decomposed at temperatures around $400{ }^{\circ} \mathrm{C}$, while $50 \%$ of the iridium complexes decomposed already at around $300^{\circ} \mathrm{C}$. The measurements indicate a possible trend in the stability, in line with the arguments given above. The decomposition either took place in the gas phase or in contact with the hot quartz surface. The exact reaction mechanism is not known.

\subsection{Volatility and interaction with $\mathrm{SiO}_{2}$ and $\mathrm{Au}$}

In all experiments, adsorption enthalpies of transitionmetal carbonyl complexes on all studied surfaces were evaluated to be less than $50 \mathrm{~kJ} / \mathrm{mol}$ (see Table 2). Such values are a strong indication for physisorption processes and are comparable to the values associated with the adsorption of group 8 tetroxides on surfaces like $\mathrm{Si}_{2} \mathrm{~N}_{3}$ [47], $\mathrm{SiO}_{2}[48,49], \mathrm{Al}_{2} \mathrm{O}_{3}$, or $\mathrm{Au}$ [30].

From the measured break-through curves of the isothermal chromatography experiments with technetium and rhodium, no adsorption enthalpies could be extracted due to the influence of precursor effects, which cannot be quantified. Instead, the apparent $T_{50 \%}$ values were extracted. These are compatible with the assumption that the interaction is due to physisorption processes. The breakthrough curves obtained for ${ }^{109} \mathrm{Rh}$ indicate physisorption of a rhodium and/or ruthenium carbonyl complex on quartz. The adsorption temperature and adsorption enthalpy evaluated for molybdenum are also typical for physisorption.

The group 6 hexacarbonyl complexes are the best studied ones. Also their adsorption behaviour has been of research interest before. Several studies about the adsorption of hexacarbonyl complexes on $\mathrm{Al}_{2} \mathrm{O}_{3}$ and $\mathrm{SiO}_{2}$ are described in the literature [39, 50-52]. In reference [39], molybdenum hexacarbonyl is reported to initially physisorb on silicon dioxide; under vacuum at temperatures above $10{ }^{\circ} \mathrm{C}$, some of the carbonyl ligands are lost, and surface complexes are formed. For chromium and tungsten hexacarbonyl, only physisorption was observed. This is in agreement with the $-\Delta H_{\text {ads }}$ values evaluated in this work, which are also indicative of physisorption processes.

Recently, the adsorption enthalpies of single group 6 hexacarbonyl complexes including seaborgium hexacarbonyl on a quartz surface have been calculated [53]. The following trend in $-\Delta H_{\text {ads }}$ has been predicted:
Table 2: $-\Delta H_{\text {ads }}$ of the assumed transition-metal-carbonyl complexes as evaluated from the different chromatography methods (IC - isothermal chromatography, COMPACT thermochromatography in a detector channel and different adsorbing surfaces).

\begin{tabular}{llrrr}
\hline Group & Complex & $\begin{array}{r}\text { IC } \\
\mathrm{SiO}_{2}\end{array}$ & $\begin{array}{r}\text { COMPACT } \\
\mathrm{SiO}_{2}\end{array}$ & $\begin{array}{r}\text { COMPACT } \\
\text { Au }\end{array}$ \\
\hline 6 & $\mathrm{Mo}(\mathrm{CO})_{6}$ & $42.5 \pm 2.5$ & & \\
6 & $\mathrm{~W}(\mathrm{CO})_{6}$ & & $46.5 \pm 2.5$ & $41_{-4}^{+3}$ \\
7 & $\operatorname{Re}(\mathrm{CO})_{\mathrm{y}} \mathrm{X}$ & $43 \pm 3$ & & \\
8 & $\mathrm{Os}(\mathrm{CO})_{5}$ & & $43.5_{-2.5}^{+3.5}$ & $39 \pm 4$ \\
9 & $\mathrm{Ir}(\mathrm{CO})_{\mathrm{y}} \mathrm{X}$ & $37 \pm 3$ & & \\
\hline
\end{tabular}

$\mathrm{Cr}(\mathrm{CO})_{6}<\mathrm{Mo}(\mathrm{CO})_{6}>\mathrm{W}(\mathrm{CO})_{6} \approx \mathrm{Sg}(\mathrm{CO})_{6}$, see Table 3 . This is in disagreement with our studies, where the $-\Delta H_{\text {ads }}$ of $\mathrm{W}(\mathrm{CO})_{6}$ is slightly higher than that of $\mathrm{Mo}(\mathrm{CO})_{6}$.

The adsorption enthalpy $-\Delta H_{\mathrm{ads}}$ is related to the binding energy $E_{(x)}$ by

$$
E_{(x)}=-\Delta H_{\mathrm{ads}}+0.5 \cdot R T
$$

In the case of physisorption, the binding energy can be calculated with [54]

$$
E_{(x)}=-\left(\frac{\pi}{6}\right) \cdot N \cdot C_{1} \cdot \frac{1}{x^{3}},
$$

where $N$ is the number of atoms per one cubic centimetre and $x$ is the interaction distance in centimetres.

The van der Waals constant $C_{1}$ can be expressed as [54]

$$
C_{1}=\frac{3}{2} \cdot \alpha_{\mathrm{A}} \cdot \alpha_{\mathrm{B}} \cdot \frac{E_{\mathrm{A}} \cdot E_{\mathrm{B}}}{E_{\mathrm{A}}+E_{\mathrm{B}}}
$$

Here, $\alpha_{\mathrm{A}}$ and $\alpha_{\mathrm{B}}$ are the polarizabilities of the adsorbed molecule $\mathrm{A}$ and the surface B. $E_{\mathrm{A}}$ and $E_{\mathrm{B}}$ are the average dipole transition energies. In reference [55], the average dipole energies were replaced by the reciprocal of the first ionization potential. The physisorption energy can thus be written as

$$
E_{(x)}=-\frac{\pi}{4} \cdot N \cdot \frac{1}{x^{3}} \cdot \frac{\alpha_{\mathrm{A}} \cdot \alpha_{\mathrm{B}}}{\frac{1}{I P_{\mathrm{A}}}+\frac{1}{I P_{\mathrm{B}}}}
$$

The polarizability can be calculated according to [55]

$$
\alpha_{\mathrm{B}}=\frac{3}{4 \cdot \pi \cdot N} \cdot \frac{(\varepsilon-1)}{(\varepsilon+2)},
$$

where $\varepsilon$ is the dielectrical constant of the surface material.

For the calculation of the adsorption energy on a surface material for which no data on the polarizability are 
Table 3: Data from literature taken for the calculation of the binding energy between the hexacarbonyl complexes of group 6 and $\mathrm{SiO}_{2}$ and Au surfaces, together with the calculated values of the binding energy and adsorption enthalpy. The experimentally determined adsorption enthalpies from work are also included.

\begin{tabular}{|c|c|c|c|c|c|c|c|c|c|c|}
\hline & $\begin{array}{r}{ }^{\mathrm{a}} \mathrm{IP} \\
{[\mathrm{eV}]}\end{array}$ & $\begin{array}{r}{ }^{a} \alpha \\
\text { [a.u.] }\end{array}$ & $\begin{array}{r}{ }^{b} r_{\mathrm{VdW}} \\
{[\AA]}\end{array}$ & $\begin{array}{r}\text { a }-\Delta H_{\text {ads }} \\
\text { on } \mathrm{SiO}_{2} \\
{[\mathrm{~kJ} / \mathrm{mol}]} \\
\text { predicted }\end{array}$ & $\begin{array}{r}{ }^{\mathrm{d}} E_{(x)} \text { on } \\
\mathrm{SiO}_{2} \\
{[\mathrm{~kJ} / \mathrm{mol}]}\end{array}$ & $\begin{array}{r}\text { Calc. } \\
\text { d }-\Delta H_{\mathrm{ads}} \\
\text { on } \mathrm{SiO}_{2} \\
{[\mathrm{~kJ} / \mathrm{mol}]}\end{array}$ & $\begin{array}{r}\text { Measured } \\
-\Delta H_{\mathrm{ads}} \\
\text { on } \mathrm{SiO}_{2} \\
{[\mathrm{~kJ} / \mathrm{mol}]}\end{array}$ & $\begin{array}{r}{ }^{\mathrm{e}} E_{(x)} \\
\text { on } \mathrm{Au} \\
{[\mathrm{kJ} / \mathrm{mol}]}\end{array}$ & $\begin{array}{r}\text { Calc. } \\
\text { e }-\Delta H_{\text {ads }} \\
\text { on Au } \\
{[\mathrm{kJ} / \mathrm{mol}]}\end{array}$ & $\begin{array}{r}\text { Measured } \\
-\Delta H_{\mathrm{ads}} \\
\text { on } \mathrm{Au} \\
{[\mathrm{kJ} / \mathrm{mol}]}\end{array}$ \\
\hline $\mathrm{Cr}(\mathrm{CO})_{6}$ & 9.07 & 133.24 & 3.161 & $45.4 \pm 2.5$ & -35.7 & 35.8 & - & -45.0 & 45.2 & - \\
\hline $\mathrm{Mo}(\mathrm{CO})_{6}$ & 9.003 & 156.41 & 3.244 & $48.1 \pm 2.5$ & -38.6 & 38.7 & $42.5 \pm 2.5$ & -48.7 & 48.8 & - \\
\hline $\mathrm{W}(\mathrm{CO})_{6}$ & 8.925 & 151.54 & 3.2295 & $46.5 \pm 2.5$ & -37.7 & 37.8 & $46.5 \pm 2.5$ & -47.6 & 47.8 & $41_{-4}^{+3}$ \\
\hline $\mathrm{Sg}(\mathrm{CO})_{6}$ & & 159.43 & & $46.2 \pm 2.5$ & & & & & & \\
\hline
\end{tabular}

a [53]; ${ }^{b}$ estimated from the crystal structures [57-59], which are orthorombic, the $r_{\mathrm{vdw}}$ should be around half of the shortest distance between two metal atoms (rhomboeder-width ${ }^{\mathrm{c}}$ in the crystal structure); ${ }^{\mathrm{d}}$ calculated according to equation (6); ${ }^{\mathrm{e}}$ calculated according to equation (4).

available, the following equation can thus be applied

$$
E_{(x)}=-\frac{3}{16} \cdot \frac{(\varepsilon-1)}{(\varepsilon+2)} \cdot \frac{\alpha_{\mathrm{A}}}{\left(\frac{1}{I P_{\mathrm{A}}}+\frac{1}{I P_{\mathrm{B}}}\right) \cdot x^{3}}
$$

The adsorption enthalpies on $\mathrm{SiO}_{2}$ were calculated according to equations (1) and (6). The dielectrical constant of silicon dioxide is 3.81 [54] and the ionization potential is $11.7 \mathrm{eV}$ [47].

For the calculation of the adsorption enthalpies on gold, equations (1) and (4) were used. The ionization potential of gold is $9.2 \mathrm{eV}$ [56] and the polarizabilty is $5.8 \times 10^{-24} \mathrm{~cm}[56]$.

For the hexacarbonyl complexes, the $E(x)$ and $-\Delta H_{\text {ads }}$ were calculated, and the results are given in Table 3.

According to the calculations, adsorption on gold is expected to occur at higher temperatures than on $\mathrm{SiO}_{2}$, as the predicted $-\Delta H_{\text {ads }}$ values on gold are higher than those on silicon dioxide. However, this is in disagreement with the experimental data. Adsorption of tungsten and osmium carbonyl complexes on Au surfaces occurred at lower temperatures than on $\mathrm{SiO}_{2}$ surfaces, and the experimental adsorption enthalpies on gold are slightly higher than those on $\mathrm{SiO}_{2}$. One reason might be that gold carbonyl surface complexes formed in our experiments. If so, adsorption would not have occurred on a clean gold metal surfaces.

\section{Summary and outlook}

Our work presents a promising step on the way to the synthesis of fragile compounds of transactinides. Metal carbonyl complexes turned out to be a very promising and in- teresting chemical system, which is accessible experimentally also for transactinides, if studied after a physical preseparation.

It has been demonstrated that isotopes of the $4 d$ transition metals molybdenum, technetium, ruthenium, and rhodium produced in the neutron-induced fission of ${ }^{249} \mathrm{Cf}$ form volatile carbonyl complexes upon thermalization in a carbon-monoxide containing recoil chamber. However, precursor effects complicate the interpretation of the data. Short-lived isotopes of the $5 d$ elements tungsten, rhenium, osmium, and iridium were synthesised in nuclear fusion reactions at TASCA. These elements form volatile carbonyl complexes upon thermalization in a carbon monoxide containing atmosphere in an RTC behind a recoil separator. These complexes were rapidly transported in a carrier gas-stream. In these measurements, no precursor effects disturbed the interpretation.

All experiments showed that in-situ carbonyl chemistry is a very effective and fast method. Additionally, carbonyl chemistry can be combined with gas-phase chromatography. Adsorption studies of several carbonyl complexes on silicon dioxide or gold surfaces showed these complexes to physisorb at temperature below $-40{ }^{\circ} \mathrm{C}$. This allows studies with on-line thermochromatography detectors like COMPACT. We determined the thermal stabilities of some of the complexes. It was shown that they decompose at temperatures around $300-400{ }^{\circ} \mathrm{C}$ in contact with a quartz surface. Here, the interactions of the surface material with the complexes may play an important role. Therefore, further decomposition studies with different hot surfaces will be required to allow for an improved understanding.

All experiments were conducted under conditions compatible with a transactinide experiment. Carbonyl chemistry appears to be suitable for studies of the trans- 
actinide elements seaborgium, bohrium, hassium, and meitnerium. Studying the formation and adsorption of seaborgium hexacarbonyl appears to be a first and most promising step. The synthesis of this compound would result in the first volatile transactinide complex with the metal in oxidation state zero. Carbonyl-complexes would also allow the fast chemical preparation of clean samples suitable for nuclear spectroscopy by their deposition on a cooled detector surface, ideal for measurements with high efficiency under low background conditions.

Acknowledgement: We thank the staff from the TRIGA Mainz reactor and the mechanical and electronics workshops at the Institut für Kernchemie at the University of Mainz as well as the GSI target laboratory for their support. We thank the GSI ion source and accelerator staff for stable beams. We thank Valeria Pershina and Josef Anton for their support with theoretical calculations and fruitful discussion. We gratefully acknowledge financial support of the Helmholtz Institute Mainz, the Research Center Elementary Forces and Mathematical Foundations (EMG), the BMBF under contract No. 06MZ223I and 06MZ7164, the Helmholtz association under contract No. VH-NG-723, and the Swiss National Science Foundation under contract No. 200020, 126639 and 200020_244511.

\section{References}

1. Türler, A., Pershina, V.: Advances in the production and chemistry of the heaviest elements. Chem. Rev. 113, 1237-1312 (2013).

2. Kratz, J. V.: Chemistry of Transactinides. In: Vértes, A., Nagy, S., Klencsár, Z., Lovas, R. G., Rösch, F. (eds.) Handbook of Nuclear Chemistry, pp. 925-1004. Springer US (2011).

3. Zvara, I.: The Inorganic Radiochemistry of Heavy Elements. Methods for Studying Gaseous Compounds, $1^{\text {st }}$ Ed., Springer (2008).

4. Schädel, M.: Chemistry of the superheavy elements. Angew. Chem. Intl. Ed. 45, 368-401 (2006).

5. Düllmann, Ch. E., Folden III, C.M., Gregorich, K. E., Hoffman, D. C., Leitner, D., Pang, G. K., Sudowe, R., Zielinski, P. M., Nitsche, H.: Heavy-ion-induced production and physical preseparation of short-lived isotopes for chemistry experiments. Nucl. Instr. Meth. Phys. Res. A 551, 528-539 (2005).

6. Mond, L., Langer, C., Quincke, F.: Action of carbon monoxide on nickel. J. Chem. Soc., Trans. 57, 749-753 (1890).

7. Herrmann, W. A.: 100 years of metal carbonyls: a serendipitous chemical discovery of major scientific and industrial impact. J. Organomet. Chem. 383, 21-44 (1990).

8. Elschenbroich, C.: Organometallchemie, 4., überarb. und erw. Aufl. Teubner-Studienbücher Chemie. Teubner, Stuttgart (2003).

9. Darling, J. H., Ogden, J. S.: Spectroscopic studies on matrixisolated metal carbonyls. Part II. Infrared spectra and struc- tures of $\mathrm{Pd}(\mathrm{CO})_{4}, \mathrm{Pd}(\mathrm{CO})_{3}, \mathrm{Pd}(\mathrm{CO})_{2}$, and PdCO. J. Chem. Soc., Dalton Trans., 1079-1085 (1973).

10. McIntosh, D., Ozin, G. A.: Synthesis of binary gold carbonyls, $\mathrm{Au}(\mathrm{CO})_{n}(n=1$ or 2$)$. Spectroscopic evidence for isocarbonyl(carbonyl)gold, a linkage isomer of bis(carbonyl)gold. Inorg. Chem. 16, 51-59 (1977).

11. Frenking, G., Fröhlich, N.: The nature of the bonding in transition-metal compounds. Chem. Rev. 100, 717-774 (2000).

12. Ehlers, A. W., Frenking, G.: Theoretical studies of the $\mathrm{M}-\mathrm{CO}$ bond lengths and first dissociation energies of the transition metal hexacarbonyls $\mathrm{Cr}(\mathrm{CO})_{6}, \mathrm{Mo}(\mathrm{CO})_{6}$ and $\mathrm{W}(\mathrm{CO})_{6}$. J. Chem. Soc., Chem. Commun., 1709-1711 (1993).

13. Ehlers, A. W., Frenking, G.: Structures and bond energies of the transition metal hexacarbonyls $\mathrm{M}(\mathrm{CO})_{6}(\mathrm{M}=\mathrm{Cr}, \mathrm{Mo}, \mathrm{W})$. A theoretical study. J. Am. Chem. Soc. 116, 1514-1520 (1994).

14. Patzschke, M., Pyykkö, P.: Darmstadtium carbonyl and carbide resemble platinum carbonyl and carbide. Chem. Comm., 1982 (2004).

15. Nash, C. S., Bursten, B. E.: Prediction of the bond lengths, vibrational frequencies, and bond dissociation energy of octahedral seaborgium hexacarbonyl, $\mathrm{Sg}(\mathrm{CO})_{6}$. J. Am. Chem. Soc. 121, 10830-10831 (1999).

16. Pyykkö, P., Desclaux, J. P.: Relativity and the periodic system of elements. Acc. Chem. Res. 12, 276-281 (1979).

17. Wiles, D. R., Baumgärtner, F.: Radiochemical transformations and rearrangements in organometallic compounds. Fortschr. Chem. Forsch. 32, 63-108 (1972).

18. Baumgärtner, F., Reichold, P.: Zur Chemie bei Kernprozessen. IV. Anwendung der Uranspaltung zu Synthese von trägerfreiem Molybdän-hexacarbonyl $\left({ }^{99} \mathrm{Mo}\right){ }^{*}$. Z. Naturforsch. 169, 945-948 (1961).

19. Wolf, G. K., Fröschen, W.: Trenn- und Identifzierungsmethoden für kurzlebige Elemente, Targetentwicklung für den Schwerionenbeschleuniger UNILAC. In: Experimente am Karlsruher Zyklotron im Jahre 1972 KFK 1783, 99-104, Kernforschungszentrum Karlsruhe, Zyklotron-Laboratorium, Karlsruhe (April/1973).

20. Even, J., Yakushev, A., Düllmann, Ch. E., Dvorak, J., Eichler, R., Gothe, O., Hild, D., Jäger, E., Khuyagbaatar, J., Kratz, J. V., Krier, J., Niewisch, L., Nitsche, H., Pysmenetska, I., Schädel, M., Schausten, B., Türler, A., Wiehl, N., Wittwer, D.: Rapidd synthesis of radioactive transition-metal carbonyl complexes at ambient conditions. Inorg. Chem. 51, 6431-6433 (2012).

21. Düllmann, Ch. E.: Physical preseparation: a powerful new method for transactinide chemists. Eur. Phys. J. D 45, 75-80 (2007).

22. Düllmann, Ch. E.: Superheavy element studies with preseparated isotopes. Radiochim. Acta 99, 515-526 (2011).

23. Semchenkov, A., Brüchle, W., Jäger, E., Schimpf, E., Schädel, M., Mühle, C., Klos, F., Türler, A., Yakushev, A., Belov, A., Beyakova, T., Kaparkova, M., Kukhtin, V., Lamzin, E., Sytchevsky, S.: The TransActinide Separator and Chemistry Apparatus (TASCA) at GSI - Optimization of ion-optical structures and magnet designs. Nucl. Instrum. Methods Phys. Res., Sect. B 266, 4153-4161 (2008).

24. Even, J., Ballof, J., Brüchle, W., Buda, R. A., Düllmann, Ch. E., Eberhardt, K., Gorshkov, A., Gromm, E., Hild, D., Jäger, E., Khuyagbaatar, J., Kratz, J. V., Krier, J., Liebe, D., Mendel, M., Nayak, D., Opel, K., Omtvedt, J. P., Reichert, P., Runke, J., Sabelnikov, A., Samadani, F., Schädel, M., Schausten, B., Scheid, N., Schimpf, E., Semchenkov, A., Thörle-Pospiech, P., Toyoshima, A., Türler, A., Vicente Vilas, V., Wiehl, N., Wunder- 
lich, T., Yakushev, A.: The recoil transfer chamber - An interface to connect the physical preseparator TASCA with chemistry and counting setups Nucl. Instrum. Methods Phys. Res., Sect. A 638, 157-164 (2011).

25. Düllmann, Ch. E., Gregorich, K. E., Pang, G. K., Dragojević, I., Eichler, R., Folden III, C. M., Garcia, M. A., Gates, J. M., Hoffman, D. C., Nelson, S. L., Sudowe, R., Nitsche, H.: Gas chemical investigation of hafnium and zirconium complexes with hexafluoroacetylacetone using preseparated short-lived radioisotopes. Radiochim. Acta 97, 403-418 (2009).

26. Eberhardt, K., Brüchle, W., Düllmann, Ch. E., Gregorich, K. E., Hartmann, W., Hübner, A., Jäger, E., Kindler, B., Kratz, J. V., Liebe, D., Lommel, B., Maier, M. Schädel, B. Schausten, E. Schimpf, A. Semchenkov, H.-J., Steiner, J., Szerypo, J., Thörle, P., Türler, A., Yakushev, A.: Preparation of targets for the gas-filled recoil separator TASCA by electrochemical deposition and design of the TASCA target wheel assembly. Nucl. Instrum. Methods Phys. Res., Sect. A 590, 134-140 (2008).

27. Ziegler, J. F., Ziegler, M. D., Biersack, J. P.: SRIM - The stopping and range of ions in matter (2010). $19^{\text {th }}$ International Conference on Ion Beam Analysis. Nucl. Instrum. Methods Phys. Res., Sect. B 268, 1818-1823 (2010).

28. Schädel, M., Ackermann, D., Andersson, L. L., Ballof, J., Block, M., Buda, R. A., Brüchle, W., Dragojević, I., Düllmann, Ch. E., Dvorak, J., Eberhardt, K., Even, J., Gates, J. M., Gerl, J., Gorshkov, A., Golubev, P., Graeger, R., Gregorich, K. E., Gromm, E., Hartmann, W., Heßberger, F. P., Hild, D., Hoischen, R., Hübner, A., Jäger, E., Khuyagbaatar, J., Kindler, B., Kojouharov, I., Kratz, J. V., Krier, J., Kurz, N., Lahiri, S., Liebe, D., Lommel, B., Maiti, M., Mendel, M., Merchan, E., Nayak, D., Nilssen, J., Omtvedt, J. P., Opel, K., Reichert, P., Rudolph, D., Sabelnikov, A., Samadani, F., Schaffner, H., Schausten, B., Schuber, R., Schimpf, E., Semchenkov, A., Stavsetra, L., Steiner, J., Szerypo, J., Thörle-Pospiech, P., Toyoshima, A., Türler, A., Uusitalo, J., Wiehl, N., Wollersheim, H. J., Wunderlich, T., Yakushev, A.: TASCA commissioning completed, GSI Scientific Report 2008, 138-139, GSI Helmholtzzentrum für Schwerionenforschung GmbH, Darmstadt (2009).

29. Düllmann, Ch. E., Ackermann, D., Brüchle, W., Heßberger, F. P., Jäger, E., Khuyagbaatar, J., Schädel, M., Schausten, B., Schimpf, E., Schött, H.-J., Semchenkov, A., Dvorak, J., Gorshkov, A., Schuber, R., Türler, A., Yakushev, A., Eberhardt, K., Hummrich, H., Kratz, J. V., Omtvedt, J. P., Opel, K. Gates, J. M., Gregorich, K. E., Dressler, R. Eichler, R., Gan, Z: TASCA as a preseparator: Recoil transfer chamber commisioning. GSI Scientific Report 2006, 146, GSI Gesellschaft für Schwerionenforschung Gmb, Darmstadt (2007).

30. Yakushev, A.: Chemical charaterization of element 108, hassium and synthesis of new hassium isotopes, Habilitation thesis, Technical University Munich, Germany (2009).

31. Yakushev, A., Gates, J. M., Türler, A., Schädel, M., Düllmann, Ch. E., Ackermann, D., Andersson, L.-L., Block, M., Brüchle, W., Dvorak, J., Eberhardt, K., Essel, H. G., Even, J., Forsberg, U., Gorshkov, A., Graeger, R., Gregorich, K. E., Hartmann, W., Herzberg, R.-D., Heßberger, F. P., Hild, D., Hübner, A., Jäger, E., Khuyagbaatar, J., Kindler, B., Kratz, J. V., Krier, J., Kurz, N., Lommel, B., Niewisch, L. J., Nitsche, H., Omtvedt, J. P., Parr, E., Qin, Z., Rudolph, D., Runke, J., Schausten, B., Schimpf, E., Semchenkov, A., Steiner, J., ThörlePospiech, P., Uusitalo, J., Wegrzecki, M., Wiehl, N.: Superheavy element flerovium (element 114) is a volatile metal. Inorg. Chem. 53, 1624-1629 (2014).

32. Stender, E., Trautmann, N., Herrmann, G.: Use of alkali halide clusters in a gas-jet recoil-transport system. Radiochem. Radioanal. Lett. 42, 291-296 (1980).

33. Wachsmuth, M., Eichler, B., Tobler, L., Jost, D. T., Gäggeler, H. W., Ammann, M.: On-line gas-phase separation of shortlived bromine nuclides from precursor selenium. Radiochim. Acta 88, 873-877 (2000).

34. Wachsmuth, M., Eichler, B., Tobler, L., Hänssler, F., Gäggeler, H., Ammann, M.: Chemical characterization of shortlived selenium and their daughter isotopes from thermal neutron induced fission of ${ }^{235} \mathrm{U}$ at a gas-jet facility. J. Radioanal. Nucl. Chem. 254, 201-208 (2002).

35. Firestone, R. B.: Fission home page. (http://ie.lbl.gov/fission. html) Data from T. R. England and Rider, B. F., Los Alamos National Laboratory, LA-UR-94-3106, ENDF-349 (1993).

36. Zvara, I.: Simulation of thermochromatographic processes by the Monte Carlo method. Radiochim. Acta 38, 95-101 (1985).

37. Even, J., et al.: Evalution of thermochromatographic experiments using Monte Carlo simulations. Radiochim. Acta, to be submitted (2014).

38. Szilagyi, R. K., Frenking, G.: Structure and bonding of the isoelectronic hexacarbonyls $\left[\mathrm{Hf}(\mathrm{CO})_{6}\right]^{2-},\left[\mathrm{Ta}(\mathrm{CO})_{6}\right]^{-}, \mathrm{W}(\mathrm{CO})_{6}$, $\left[\operatorname{Re}(\mathrm{CO})_{6}\right]^{+},\left[\mathrm{Os}(\mathrm{CO})_{6}\right]^{2+}$, and $\left[\operatorname{Ir}(\mathrm{CO})_{6}\right]^{3+}:$ A theoretical study Organometallics 16, 4807-4815 (1997).

39. Howe, R. F.: Infrared evidence for reversibility in the formation of surface carbonyl complexes. Inorg. Chem. 15, 486-488 (1976).

40. Jong, I. G. de, Wiles, D. R.: Pentacarbonyltechnetium radical. Inorg. Chem. 12, 2519-2522 (1973).

41. Webber, I., Wiles, D. R.: Radiochemical reactions in rhenium carbonyls-I: $\operatorname{Re}_{2}(\mathrm{CO})_{10}$. J. Inorg. Nucl. Chem. 38, 1103-1107 (1976).

42. Sidorenko, G. V.: Volatile technetium carbonyl compounds: Vaporization and thermal decomposition. Radiochemistry $\mathbf{5 2}$, 638-652 (2010).

43. Li, J., Schreckenbach, G., Ziegler, T.: First bond dissociation energy of $\mathrm{M}(\mathrm{CO})_{6}(\mathrm{M}=\mathrm{Cr}, \mathrm{Mo}, \mathrm{W})$ revisited: the performance of density functional theory and the influence of relativistic effects. J. Phys. Chem. 98, 4838-4841 (1994).

44. Garner, M., Chandra, D., Lau, K.: Low-temperature vapor pressures of W-, Cr-, and Co-carbonyls. J. Phase Equil. 16, 24-29 (1995).

45. Hieber, W., Lagally, H.: Über Metallcarbonyle. XXXV. Über Iridiumcarbonyl. Z. Anorg. Allg. Chem. 245, 321-333 (1940).

46. Werner, H.: Complexes of carbon monoxide and its relatives: an organometallic family celebrates its birthday. Angew. Chem. Int. Ed. Engl. 29, 1077-1089 (1990).

47. Düllmann, Ch. E., Eichler, B., Eichler, R., Gäggeler, H. W., Türler, A.: On the stability and volatility of group 8 tetroxides, $\mathrm{MO}_{4}$ ( $M=$ ruthenium, osmium, and hassium $(Z=108)$ ). J. Phys. Chem. B 106, 6679-6684 (2002).

48. Düllmann, Ch. E., Eichler, B., Eichler, R., Gäggeler, H. W., Jost, D. T., Piguet, D., Türler, A.: IVO, a device for In situ Volatilization and On-line detection of products from heavy ion reactions. Nucl. Instrum. Methods Phys. Res., Sect. A 479, 631-639 (2002).

49. Kirbach, U. W., Folden III, C.M., Ginter, T. N., Gregorich, K. E., Lee, D. M., Ninov, V., Omtvedt, J. P., Patin, J. B., Seward, N. K., 
Strellis, D. A.: The Cryo-Thermochromatographic Separator (CTS): A new rapid separation and [alpha]-detection system for on-line chemical studies of highly volatile osmium and hassium $(Z=108)$ tetroxides. Nucl. Instrum. Methods Phys. Res., Sect. A 484, 587-594 (2002).

50. Reddy, K. P., Brown, T. L.: Kinetics of surface processes for $\mathrm{Mo}(\mathrm{CO})_{6}$ on partially dehydroxylated alumina and hydroxylated alumina. Observation of $\mathrm{Mo}(\mathrm{CO})_{5}(\mathrm{ads})$. J. Am. Chem. Soc. 117, 2845-2854 (1995).

51. Myllyoja, S., Suvanto, M., Kurhinen, M., Hirva, P., Pakkanen, T. A.: Interactions of $\mathrm{M}(\mathrm{CO})_{6}(\mathrm{M}=\mathrm{Cr}, \mathrm{Mo}, \mathrm{W})$ with surface sites of $\mathrm{Al}_{2} \mathrm{O}_{3}$ : a theoretical study. Surf. Sci. 441, 454-460 (1999).

52. Myllyoja, S., Pakkanen, T. A.: Controlled deposition of chromium hexacarbonyl on silica surfaces in a fluidised bed reactor. J. Mol. Catal. A: Chem. 156, 195-203 (2000).

53. Pershina, V., Anton, J.: Theoretical predictions of properties and gas-phase chromatography behaviour of carbonyl complexes of group- 6 elements $\mathrm{Cr}$, Mo, W, and element 106 , seaborgium. J.Chem.Phys. 138, 174301-6 (2013).
54. Lide, D. R.: CRC handbook of chemistry and physics. A readyreference book of chemical and physical data, 84. ed., 2003/2004. CRC Press, Boca Raton (2003).

55. Pershina, V., Bastug, T., Fricke, B., Varga, S.: The electronic structure and properties of group 8 oxides $\mathrm{MO}_{4}$, where $\mathrm{M}=\mathrm{Ru}$, Os, and element 108, Hs. J. Chem. Phys. 115, 792 (2001).

56. Eichler, R., Schädel, M.: Adsorption of radon on metal surfaces: a model study for chemical investigations of elements 112 and 114. J. Phys. Chem. B 106, 5413-5420 (2002).

57. Whitaker, A., Jeffery, J. W.: The crystal structure of chromium hexacarbonyl. Acta Cryst. 23, 977-984 (1967).

58. Mak, T. C. W.: Crystal structure of molybdenum hexacarbonyl. Z. Kristallogr. 166, 277-281 (1984).

59. Heinemann, F., Schmidt, H., Peters, K., Thiery, D.: Crystal structure of hexacarbonyl tungsten, $\mathrm{W}(\mathrm{CO})_{6}$. Z. Kristallogr. 198, 123-124 (1992).

60. Pauling, L., Simonetta, M.: Bond Orbitals and Bond Energy in Elementary Phosphorus. J. Chem. Phys. 20, 29-34 (1952).

Supplementary material: The online version of this article (DOI: 10.1515/ract-2013-2198) provides supplementary material for authorized users. 